\title{
Multiagent simulation of evolutive plate tectonics applied to the thermal evolution of the Earth
}

\section{Combes}

CNRS UMR6285 Lab-STICC, European University of Brittany, ENIB, CERV, 25 rue Claude Chappe, F-29280 Plouzané, France (combes@enib.fr)

\section{Grigné}

CNRS UMR6538 Domaines Océaniques, European University of Brittany, Université de Brest, IUEM, rue Dumont d'Urville, F-29280 Plouzané, France

\section{Husson}

CNRS UMR6118 Géosciences Rennes, Université Rennes 1, F-35000 Rennes, France

\section{P. Conrad}

Department of Geology and Geophysics, School of Ocean and Earth Science and Technology, University of Hawai i at Mànoa, Honolulu, Hawaii 96822, USA

\section{S. Le Yaouanq and M. Parenthoën}

CNRS UMR6285 Lab-STICC, European University of Brittany, ENIB, CERV, 25 rue Claude Chappe, F-29280 Plouzané, France

\section{Tisseau}

CNRS UMR6538 Domaines Océaniques, European University of Brittany, Université de Brest, IUEM, rue Dumont d'Urville, F-29280 Plouzané, France

\section{J. Tisseau}

CNRS UMR6285 Lab-STICC, European University of Brittany, ENIB, CERV, 25 rue Claude Chappe, F-29280 Plouzané, France

[1] The feedback between plate tectonics and mantle convection controls the Earth's thermal evolution via the seafloor age distribution. We therefore designed the MACMA model to simulate time-dependent plate tectonics in a 2D cylindrical geometry with evolutive plate boundaries, based on multiagent systems that express thermal and mechanical interactions. We compute plate velocities using a local force balance and use explicit parameterizations to treat tectonic processes such as trench migration, subduction initiation, continental breakup and plate suturing. These implementations allow the model to update its geometry and thermal state at all times. Our approach has two goals: (1) to test how empirically- and analyticallydetermined rules for surface processes affect mantle and plate dynamics, and (2) to investigate how plate tectonics impact the thermal regime. Our predictions for driving forces, plate velocities and heat flux are in agreement with independent observations. Two time scales arise for the evolution of the heat flux: a linear long-term decrease and high-amplitude short-term fluctuations due to surface tectonics. We also obtain a plausible thermal history, with mantle temperature decreasing by less than $200 \mathrm{~K}$ over the last 3 Gyr. In addition, we show that on the long term, mantle viscosity is less thermally influential than tectonic processes such as continental breakup or subduction initiation, because Earth's cooling rate depends mainly on its ability to replace old insulating seafloor by young thin oceanic lithosphere. We infer that simple 
convective considerations alone cannot account for the nature of mantle heat loss and that tectonic processes dictate the thermal evolution of the Earth.

Components: 13,800 words, 16 figures, 2 tables.

Keywords: Earth's thermal history; driving forces; mantle convection; mobile plate boundaries; multiagent systems; plate tectonics.

Index Terms: 8120 Tectonophysics: Dynamics of lithosphere and mantle: general (1213); 8130 Tectonophysics: Heat generation and transport; 8149 Tectonophysics: Planetary tectonics (5475).

Received 20 December 2011; Revised 22 March 2012; Accepted 29 March 2012; Published 4 May 2012.

Combes, M., C. Grigné, L. Husson, C. P. Conrad, S. Le Yaouanq, M. Parenthoën, C. Tisseau, and J. Tisseau (2012), Multiagent simulation of evolutive plate tectonics applied to the thermal evolution of the Earth, Geochem. Geophys. Geosyst., 13, Q05006, doi:10.1029/2011GC004014.

\section{Introduction}

\subsection{Classic Approaches}

[2] Earth's thermal evolution is controlled by radioactive internal heating and secular cooling. The resulting surface heat loss has long been studied using scaling laws derived from convection models [e.g., Davies, 1980; Schubert et al., 1980; Grigné and Labrosse, 2001]. The monotonous variation of mantle temperature is generally thought to be characterized by an intrinsic timescale as long as $10 \mathrm{Gyr}$ [Guillou and Jaupart, 1995; Labrosse and Jaupart, 2007], but the magnitude of short timescale fluctuations is greater than the average thermal evolution [Grigné et al., 2005; Labrosse and Jaupart, 2007]. The time-dependence of plate tectonics in particular affects the thermal regime. Loyd et al. [2007] exemplified this impact with the subduction of the young sea floor of the Farallon plate beneath North America, and Becker et al. [2009] estimated that mantle heat flux subsequently decreased by almost $25 \%$ over 100 Myr during the Cenozoic. Similarly, the reconstruction of heat flux evolution proposed by Zhang and Zhong [2011] suggests that the breakup of Pangea is coeval with a $16 \%$ increase of surface heat loss. These results suggest that events occurring on plate tectonic timescales should not be neglected, at odds with previous numerical and parameterized approaches that neglect the multiple timescales of interaction between tectonics and convection. The underlying physics of those interactions can nevertheless be perceived by numerical investigations of the mechanical and thermal coupling between insulating lids and mantle flow. Various studies show that continents may create long wavelength patterns in the convective layer [Phillips and Bunge, 2005; Grigné et al., 2007a, 2007b] while raising the temperature beneath supercontinents [O'Neill et al., 2009; Phillips and Coltice, 2010] and in turn enhancing convective vigor for temperaturedependent viscosity models [e.g., Lenardic et al., 2005; Samuel et al., 2011]. Furthermore, timedependent simulations show that continental insulation leads to mantle overheating and to aggregation and dispersal of supercontinents [Gurnis, 1988]. Such a feedback may be responsible for a currently transient thermal state of the mantle [Zhong et al., 2007]. The extrapolation of these numerical results to the Earth would nevertheless require stable plate motions above the convective mantle, since plate tectonics is a first order characteristic of the thermal evolution of the planet [e.g., Labrosse and Jaupart, 2007; Becker et al., 2009].

[3] The challenge of making self-consistent plate tectonics arise in temperature-dependent viscosity models has been overcome by prescribing plastic yielding mechanisms in the lithosphere [Moresi and Solomatov, 1998; Tackley, 2000a, 2000b]. Long wavelength patterns emerge naturally in these models, and the resulting heat flux compares to classic scaling laws [Grigné et al., 2005]. Unfortunately, such settings are not Earth-like in the sense that they have broad plate boundaries and often subduction zones that are double-sided. One-sided Earth-like subduction zones can be obtained when a free surface is implemented, along with a weak oceanic crust that acts as a decoupling layer between the subducting slab and the mantle wedge [Crameri et al, 2012]. However, even with transient Earthlike subduction zones, simulations evolve towards a stagnant-lid regime and no continuous plate tectonics can be obtained. Continents may enhance and focus stresses in the lithosphere and therefore help to create stable plate tectonics [e.g., Rolf and 
Tackley, 2011]. However, simulations exhibiting stable plate tectonics over several billions years, with both one-sided subduction zones and continents, have yet to be realized. Furthermore, no scaling law for the heat flux has so far been proposed that includes continents and an evolving configuration of plate tectonics.

[4] An alternative approach to this problem is to directly impose lithospheric plates. In this case, rigid buoyant plates are integrated into the model as boundary conditions based on a force balance approach [Gable et al., 1991; Lowman et al., 2001; Monnereau and Quéré, 2001]. Recent improvements consider evolutive plate boundaries, so that plates can be created or subducted [Gait and Lowman, 2007; Lowman et al., 2008; Stein and Lowman, 2010]. In this context, highly timedependent features are observed: surface heat flux may fluctuate by $75 \%$ and plate velocities by $60 \%$ over 200 Myr [Gait et al., 2008]. Such models highlight some phenomena that influence the thermal regime, but without continents that may control plate boundary motions, they do not account for the feedback interactions between the sea floor age distribution and continental aggregation and dispersal.

\subsection{Multiagent Approach}

[5] Describing the coupling between continents and oceanic lithosphere with differential equations is a major challenge of mantle convection simulations. For instance, modeling subduction initiation or continent aggregation and dispersal mechanisms faces the problem of complexity description, because these phenomena remain poorly understood and consequently, cannot be described with differential equations. This usually prevents classic numerical modeling methods from running quantitative simulations of the Earth's long term thermal evolution.

[6] Multiagent systems (MAS) present an alternative method to fully explore the influence of surface tectonics on the time-dependence of mantle heat loss. Classic numerical methods may provide grid calculation results in three dimensions, but the user does not have access to the forces that control plate tectonics. Multiagent simulations [Weiss, 1999; Ferber, 1999; Wooldridge, 2002] allow for the experimentation of explicit mechanisms and related hypotheses: physical individual-based models focus on the interactions between mobile entities that describe complex phenomena on a global scale. Agents are autonomous entities collecting information from their environment in order to make decisions controlled by behavior laws. These laws are prescribed in a physical (or economic, biological, etc.) model that may be improved and complexified at will, through individual properties and interactions (perception, communication) between them [e.g., Müller et al., 2003; Combes et al., 2010]. An intuitive vision of MAS considers that each agent is a cyclic engine operating in three steps: (1) Perception: it perceives its environment through specialized sensors, (2) Decision: it decides on its behavior following its sensors and internal state, (3) Action: it behaves by modifying its internal state and direct environment. Multiagent systems are commonly used for biology and medicine [e.g., Kerdelo et al., 2002; Vicari et al., 2003; Corradini and Merelli, 2005; Boruchov et al., 2007], molecular dynamics [e.g., Gordon-Spears and Spears, 2002; Coulon et al., 2008; Combes et al., 2010] and fluid dynamics [Müller et al., 2003; Parenthoën et al., 2004]. Few geophysical studies have used multiagent systems until recently [e.g., Marcenac and Giroux, 1998], although cellular automata have been used successfully to describe dune dynamics [Narteau, 2007; Narteau et al., 2009; Zhang et al., 2010].

[7] In our approach, behaviors do not need to be described by analytical laws: when only an empirical law is available, this can still be integrated in the model, as opposed to more common approaches based on the resolution of differential equations on a grid. Observations gathered over decades of research, which cannot yet be mathematically described, can be used within our new paradigm. Future observations and scientific results may also be easily added into MACMA. In multiagent systems, the principle of causality allows the user to reconstruct the mechanism of a complex phenomenon, since the architecture of the model permits explicit changes in the nature and the number of the processes that are used [Pawlowski et al., 2009]. Because our multiagent approach does not solve differential equations on grids, our method has a very low computational cost, which renders real time simulations performable on any personal computer. This grants our method a flexibility similar to experimental sciences. Since multiagent simulations also permit a direct access to numerical methods, any user can build "in virtuo experiments" [Desmeulles et al., 2009]. Finally, it can be noted that the userfriendliness of the simulation makes it a powerful resource for teaching purposes and model experimentation.

[8] In this paper, we first explore the coupling between plate tectonics and mantle evolution with explicit mechanisms based on analytical and 
empirical behavior laws that can be investigated independently. Secondly, we simulate timedependent plate tectonics with mobile plate boundaries and without prescribing the number of plates. In order to capture the complex coupling between plate dynamics and Earth's thermal evolution, our approach is based on two main requirements: (1) all the mechanisms used to model plate tectonics must be expressed without directly solving differential equations of conservation, and (2) plate boundaries must be mobile to permit plate creation and destruction. Four types of agents interact in a 2D-cylindrical planet: convection cells, lithospheric plates, continents, and plate boundaries (ridges, subduction zones). Interactions are controlled either by analytical laws regarding temperature, heat flux, driving forces and velocity calculations, or empirical laws for kinematic interactions between plates. Plate velocities are computed at all times by solving a force balance [e. g., Lithgow-Bertelloni and Richards, 1998; Conrad and Lithgow-Bertelloni, 2004] that accounts for analytical formulations of ridge push [Parsons and Richter, 1980], slab pull and bending [Conrad and Hager, 1999a, 1999b; Buffet, 2006], and Newtonian mantle drag or slab suction in the mantle. Following a half-space cooling model [e.g., Turcotte and Schubert, 2002], oceanic plate thickness and heat loss are age-dependent. Empirical behavior laws are prescribed to drive plate boundary creation, evolution, migration, and disappearance. Finally, following the recent studies by Coltice et al. [2007] and O'Neill et al. [2009] for an internally heated mantle, a mechanism for supercontinental breakup is proposed.

[9] In this paper, we build a multiagent model, entitled MACMA for MultiAgent Convecting Mantle, that simulates coupled plate tectonics and mantle evolution using the multiagent approach. The modeling paradigm proposed by our model is a virtual laboratory that allows for the coupling of analytical and phenomenological laws to model complex phenomena. Our model is first used to study specific tectonic contexts and their resulting kinematics, such as plate velocity evolution through surface structure changes, or plate velocity dependence on plate boundary nature, by comparing our results to observations. Then, the model is used to investigate the coupling between tectonics, sea floor age distribution and oceanic heat flux evolution over 300 million years. Finally, Earth's long-term thermal evolution is investigated over several billion years by examining the impact of two behavior laws for subduction initiation and two physical parameters concerning mantle rheology and surface dynamics, in order to determine how important the tectonic parameters are compared to convective parameters.

\section{Geophysical Model}

\subsection{Model Overview}

[10] The surface of the 2D cylindrical planet is covered by mobile plates with evolutive boundaries, and continents, if any, are superimposed over the plates, leading to a succession of continental and oceanic sections. Figure 1 illustrates the plate and convective cell distributions for a simulation that includes continents. The mantle is divided into an upper and a lower part, both having Newtonian rheologies. We assume a diffusion creep mechanism in a dry mantle [Karato and $W u, 1993]$, leading to a temperature-dependent viscosity expression:

$$
\eta\left(T_{m}\right)=\eta^{p} \exp \left[\frac{E}{R}\left(\frac{1}{T_{m}}-\frac{1}{T_{m}^{p}}\right)\right]
$$

with $E$ the activation energy, $R$ the ideal gas constant, $\eta^{p}$ the current viscosity and $T_{m}^{p}$ the corresponding temperature, which are both used as reference values. Slabs can sink down to the core mantle boundary, and, following Conrad and LithgowBertelloni [2002, 2004], our model accounts for slab pull and resistance to downgoing motion in the upper mantle only: the remainder of the slab weight is considered to drive the slab suction force. At the surface, mid-oceanic ridge motion is driven by the diverging plates' velocities, and trench migration is controlled by upper plate motion, allowing back-arc basin formation in extensive cases.

[11] The initial state of the simulation and its spatial resolution are prescribed by the user. One can set plate boundary and continent positions, along with the age of each plate section extremity. Then, the age distribution is approximated by a linear variation along the section. Our multiagent scheduling is the following: at a given time step, the structure evolution is computed first, by applying plate reorganization rules until no interface coincidence or lithosphere breakup occurs; then, each plate's velocity is calculated independently using a local force balance that accounts for the current features of the system: plate extent, age, boundary nature and underlying mantle temperature. Plate boundary velocities are subsequently computed, and their positions calculated in order to determine the new plate extent and to update the surface heat flux distribution and the mantle temperature. Before 


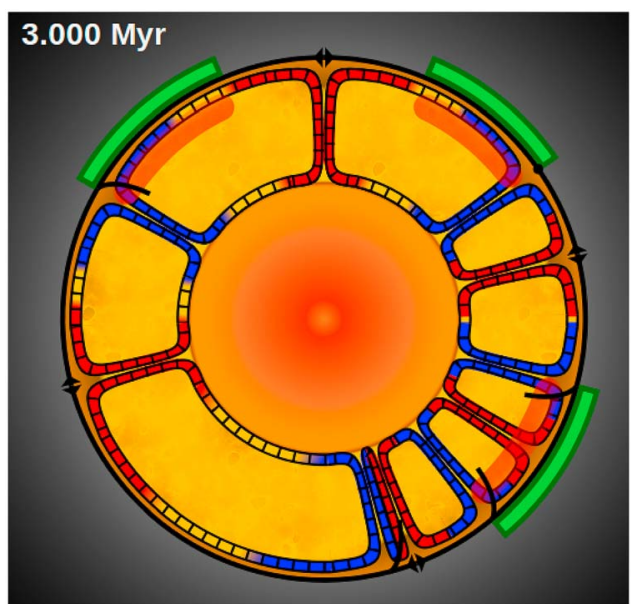

Figure 1. Overview of the simulation environment. The MACMA model describes a 2D cylindrical planet, displaying convection cells (upwellings in red and downwellings in blue). Continents (green) are superimposed onto lithospheric plates (black). Plate boundaries are mid-oceanic ridges (black triangles) and subduction faults (sinking slabs). Orange layers beneath continents represent the temperature elevation due to continental insulation (see text for more details). The time elapsed since the beginning of the simulation is noted in the top left corner.

calculating a new force balance, sequential transformation mechanisms are checked, so that the global structure is updated in the next time step: spontaneous plate sinking or collision between ridges and trenches may reorganize the plate distribution. The whole scheduling process is described in detail in the auxiliary material. ${ }^{1}$

[12] In a given geometrical state, the global heat balance is used to update the mantle temperature $T_{m}$ at time $t$ :

$$
M C_{p} \frac{d T_{m}}{d t}=-\left\langle q_{o c}\right\rangle S_{o c}+\underbrace{\sum_{i} Q_{i} e^{-\lambda_{i} t}}_{Q_{\text {radio }}(t)}
$$

where $M$ is the mass of the planet and $C_{p}$ its thermal capacity [Labrosse and Jaupart, 2007]. All parameters are defined in Table 1. The first and second terms on the right-hand side of the equation are the average heat loss through the oceanic lithosphere and the radiogenic heat production, respectively. Considering a depleted mantle, radiogenic heating rates $Q_{i}$ and decay constant $\lambda_{i}$ for each isotope $i$ are derived from the CI chondrite model by Jochum et al. [1983]. The integration of the surface heat flux $q_{o c}$ is based on the classic half-space cooling

\footnotetext{
${ }^{1}$ Auxiliary materials are available in the HTML. doi:10.1029/ $2011 \mathrm{GC} 004014$.
}

model [e.g., Turcotte and Schubert, 2002] applied to the oceanic lithosphere of surface $S_{o c}$ :

$$
q_{o c}(t, \tau)=\frac{k\left(T_{m}(t)-T_{0}\right)}{\sqrt{\pi \kappa \tau}}
$$

where $\tau$ is the age at a given point of the lithosphere, $\kappa$ the thermal diffusivity of the mantle and $k$ its thermal conductivity. In addition, a thermal erosion process (small scale convection) limits plate thickening after a critical age that is calculated in section 2.3. After this age, surface heat flux is thus constant for a given mantle temperature. A maximum heat flux value $q_{\max }$ may be chosen in order to assess the influence of the axial zone on mantle cooling. This limit is not mathematically required because the integral of equation (3) converges for $\tau=0$, but heat fluxes observed at ridge axis are not infinite. We carried out experiments to test the effect of $q_{\text {max }}$, which showed no significant influence of this limit on the total cooling rate. These results are displayed in the auxiliary material.

\subsection{Dynamic Laws}

[13] Our force balance accounts for ridge push RP and slab pull SP [Forsyth and Uyeda, 1975; Carlson, 1981, 1983; Parsons and Richter, 1980], slab bending B [Buffet, 2006], and viscous drag in

Table 1. Model Parameters

\begin{tabular}{ll}
\hline \multicolumn{1}{c}{ Parameter } & \multicolumn{1}{c}{ Value } \\
\hline$\alpha$, thermal expansivity & $2.5 \times 10^{-5} \mathrm{~K}^{-1}$ \\
$\kappa$, thermal diffusivity & $8 \times 10^{-7} \mathrm{~m}^{2} / \mathrm{s}$ \\
$C_{p}$, thermal capacity & $1200 \mathrm{~J} / \mathrm{kg} / \mathrm{K}$ \\
$\rho_{m}$, total mantle density & $4.5 \times 10^{3} \mathrm{~kg} / \mathrm{m}^{3}$ \\
$\rho_{\text {um }}$, upper mantle density & $3.25 \times 10^{3} \mathrm{~kg} / \mathrm{m}^{3}$ \\
$\rho_{p l}-\rho_{\text {um }}$, mass excess for a & $65 \mathrm{~kg} / \mathrm{m}^{3}$ \\
$\quad$ slab & \\
$g$, gravitational acceleration & $10 \mathrm{~m} / \mathrm{s}^{2}$ \\
$M$, mass of the Earth & $6 \times 10^{24} \mathrm{~kg}$ \\
$\eta_{p l}$, plate viscosity & $10^{23} \mathrm{~Pa} . \mathrm{s}$ \\
$\eta_{m}^{p}$, present lower mantle & $10^{22} \mathrm{~Pa} . \mathrm{s}$ \\
$\quad$ viscosity & $10^{21} \mathrm{~Pa} . \mathrm{s}$ \\
$\eta_{u m}^{p}$, present upper mantle & \\
$\quad$ viscosity & $2900 \mathrm{~km}$ \\
$d$, total mantle thickness & $670 \mathrm{~km}$ \\
$D$, upper mantle thickness & $390 \mathrm{~km}$ \\
$R_{\text {min }}$, radius of curvature & \\
$U$, plate velocity & \\
$\tau_{\text {subd }}^{p}$, current critical age & \\
$\tau$, lithosphere age & \\
$H$, plate thickness & \\
$L$, plate extent & \\
$a$, continental aspect ratio & \\
$h$, advection thickness & \\
$F_{\text {lim }}$, continental strength & \\
$E$, activation energy & \\
\hline
\end{tabular}


the mantle. The latter is further decomposed into horizontal mantle drag MD and viscous drag parallel to the slab VS. Slab suction SS is also taken into account if the slab sinks into the lower mantle [Conrad and Lithgow-Bertelloni, 2002, 2004]. Considering a mantle with infinite Prandtl number, the inertial term of the Navier-Stokes equation can be neglected compared to the buoyancy and viscous terms, which leads to the following force balance:

$$
R P+S P+B+M D+V S+S S=0
$$

Following [Parsons and Richter, 1980], ridge push is given by

$$
R P=\alpha \kappa g \rho_{m}\left(T_{m}-T_{0}\right) \tau_{s}
$$

with $\tau_{s}$ the maximal age of the oceanic lithosphere section, $g$ the gravitational acceleration, $\rho_{m}$ the density, $\alpha$ the thermal expansivity and $T_{m}$ the temperature of the upper mantle.

[14] Slab pull $S P$ and bending $B$ are calculated according to the formulation of Buffet [2006], by imposing the curvature of the plate. In order to focus on the velocity contrast between young and old lithospheres, the thermal thickness $H$ of the plate derives from the half-space cooling model [Turcotte and Schubert, 2002], as a function of the age $\tau$ of a given point of the oceanic lithosphere:

$$
H(\tau)=A \sqrt{\kappa \tau}
$$

where $A$ is a constant that depends on the thermal definition of the lithosphere, which we describe in the auxiliary material. The slab pull formulation from Buffet [2006] depends on the slab mass excess $\rho_{p l}-\rho_{u m}$ and is adapted to the depth $Z(t)$ reached by the slab at all times:

$$
S P=\left(\rho_{p l}-\rho_{u m}\right) g H\left(\tau_{s}\right) Z .
$$

The bending force explicitly depends on the plate velocity $U$, and thus on the subduction history of the plate:

$$
B=-\frac{2}{3} \eta_{p l} U\left(\frac{H\left(\tau_{s}\right)}{R_{\min }}\right)^{3}
$$

where $\eta_{p l}$ is the plate viscosity. The radius of curvature $R_{\min }$ is set to $390 \mathrm{~km}$, its average value on Earth [Wu et al., 2008].

[15] The horizontal shear force $M D$ beneath the plate is assumed to occur over half the thickness $d$ of the mantle:

$$
M D=-\epsilon \eta_{m} \frac{U}{d / 2} L
$$

where $L$ is the plate length and $\epsilon \eta_{m}$ is the equivalent viscosity for a double layer of viscosity $\eta_{u m}$ over $670 \mathrm{~km}$ and $\eta_{m}$ over $780 \mathrm{~km}$, leading to $\epsilon=0.2$ as demonstrated in the auxiliary material. Considering the same viscous boundary layer thickness for slabs [Grigné et al., 2005], the shear stress VS exerted on both sides of a slab is

$$
V S=-2 \eta_{u m} \frac{U}{d / 2} Z
$$

where $\eta_{u m}$ is the upper mantle viscosity and $Z$ is the slab length in the upper mantle only. In addition, following Conrad and Lithgow-Bertelloni [2002, 2004], slab suction accounts for the slab weight in the lower mantle: slabs in the upper mantle pull directly on surface plates driving their rapid motion toward subduction zones. Slabs descending in the lower mantle induce mantle flow patterns that excite the slab suction mechanism. This flow tends to push both overriding and subducting plates toward subduction zones. The suction force $S S$ is expressed as a shear stress exerted on the lower part of the slab, and is transmitted to the horizontal plate via mantle flow:

$$
S S=\eta_{m}\left(T_{m}\right) \frac{V_{s}}{d / 2}(Z-D)
$$

where $D$ is the upper mantle thickness and $V_{s}$ is the vertical velocity of the slab. Considering that this part of the slab weight is entirely supported by the viscous mantle, $V_{s}$ may be described by the Stokes velocity [Guillou-Frottier et al., 1995; Griffiths et al., 1995; Goes et al., 2011]. Our model thus assumes the same value of $V_{s}$ for every slab, which is inversely proportional to the average mantle viscosity:

$$
V_{s}=V_{s}^{p} \frac{\eta_{m}^{p}}{\eta_{m}\left(T_{m}\right)}
$$

where $V_{s}^{p}=12 \mathrm{~mm} / \mathrm{yr}$ is the current inferred average slab velocity in the lower mantle [van der Meer et al., 2010]. The slab velocity $V_{s}$ depends on the thermal state of the mantle via the temperaturedependent viscosity incorporated in the model.

\subsection{Kinematic Laws}

[16] Our model uses analytical laws to calculate time-dependent force balances, plate velocities, heat flux and temperature in a cylindrical geometry. However, this is not sufficient to simulate Earthlike plate tectonics and mantle convection. For instance, the oceanic lithosphere has a limited 
thickening capability [Carlson and Johnson, 1994; Davaille and Jaupart, 1994], subduction zones are one-sided, and plates may be sutured or completely subducted, since plate boundaries are mobile. A multiagent approach is optimal for simulating such a complex system, because empirical laws can be added to the multiagent model in order to make agents interact in a realistic way, without altering the dynamics.

[17] Limited thickening. The plate age used in the force balance for the ridge push, slab pull or bending forces is the age $\tau_{s}$ of the oceanic section adjacent to the corresponding boundary. Observed plate thickness is presently capped to its value at 80 Myr [Carlson and Johnson, 1994; Turcotte and Schubert, 2002], but we need to model a temperature-dependent critical age when studying Earth's thermal evolution with a temperaturedependent viscosity. Our model assumes such a critical age in both the force balance (equation (4)) and heat flux computation (equation (3)).

[18] Considering a convective criterion for the onset of small scale convection beneath the oceanic lithosphere, and using the viscosity law (equation (1)), we obtain a temperature-dependent critical age $\tau_{c}$ for the limitation of oceanic lithosphere thickening, that writes

$$
\tau_{c}=\tau_{c}^{p}\left(\frac{T_{m}^{p}-T_{0}}{T_{m}-T_{0}}\right)^{2 / 3} \exp \left(\frac{2 E}{3 R}\left(\frac{1}{T_{m}}-\frac{1}{T_{m}^{p}}\right)\right) .
$$

Calculation details are provided in the auxiliary material. This result is in agreement with previous parametrizations based on numerical simulations or laboratory experiments, which also obtain a critical age $\tau_{c}$ proportional to $R a^{-2 / 3}$ [Davaille and Jaupart, 1994; Korenaga, 2003; Huang et al., 2003; Dumoulin et al., 2005]. However, contrary to these studies, our approach explicitly accounts for the current critical age $\tau_{c}^{p}$. The evolution of critical age $\tau_{c}$ is presented on Figure 2 as a function of $T_{m}$, for different values of the activation energy $E$.

[19] Subduction initiation. The mechanism that leads to subduction initiation remains poorly understood, but many processes for the initiation of subduction have been proposed [e.g., McKenzie, 1977; Cloetingh et al., 1989; Mueller and Phillips, 1991; Hall et al, 2003; Crameri and Kaus, 2010; Nikolaeva et al., 2011], either along passive margins or at transform faults and fracture zones. These rely on the brittle behavior of either the oceanic or the continental lithosphere and do not involve the viscosity of the mantle as a key parameter. Because all heat loss parameterization schemes depend on the maximum age of oceanic plates [Labrosse and Jaupart, 2007], we propose a simple law that accounts for the temperature dependence of spontaneous subduction age, based on the current age of subduction initiation. If the oceanic lithosphere keeps thickening with age at passive margins (i.e., it is not affected by small-scale convection), it will eventually achieve a critical thickness for which the negative buoyancy force of this lithosphere exceeds what can be supported at the margin. As the stronger part of the oceanic lithosphere is located in a semi-brittle semi-ductile layer, whose strength does not depend on depth nor temperature [e.g., Kirby, 1983], we consider that the yield stress for subduction initiation is constant, as is done in models of mantle convection that generate plates thanks to a viscoplastic rheology [Tackley, 2000a, 2000b]. Our model thus assumes the same critical buoyancy at any time for any mantle temperature $T_{m}$. Therefore, the critical age $\tau_{\text {subd }}$ at which a slab attached to a continent will start subducting can be derived from the half-space cooling model displayed in the auxiliary material:

$$
\tau_{\text {subd }}=\tau_{\text {subd }}^{p}\left(\frac{T_{m}^{p}-T_{0}}{T_{m}-T_{0}}\right)^{2} .
$$

Figure 2 presents the critical ages for both the onset of small scale convection, which depends on the activation energy $E$, and for subduction initiation, considering $T_{m}^{p}=1600 \mathrm{~K}$. We can see that in our model, for high $\mathrm{E}$ and low mantle temperatures, subduction may occur before the onset of small scale convection.

[20] Although this method does not describe how subduction actually initiates [McKenzie, 1977; Cloetingh et al., 1989], we believe that our simple scaling reasonably represents how the age of subduction initiation evolves as a function of mantle temperature. Since unlimited thickening of the oceanic lithosphere can occur only at continental margins in our setting, the model assumes no subduction initiation when the overriding plate is an oceanic one. Although subduction processes initiating at fracture zones have been proposed by Toth and Gurnis [1998], Hall et al [2003] and Stern [2004], which could be described in principle by a supplementary law, incidences of subduction initiation within ocean basins are rare on current Earth, and ocean-ocean subduction is not considered in the present model.

[21] Kinematics of plate boundaries. Even though the mechanism that induces one-sided subduction 


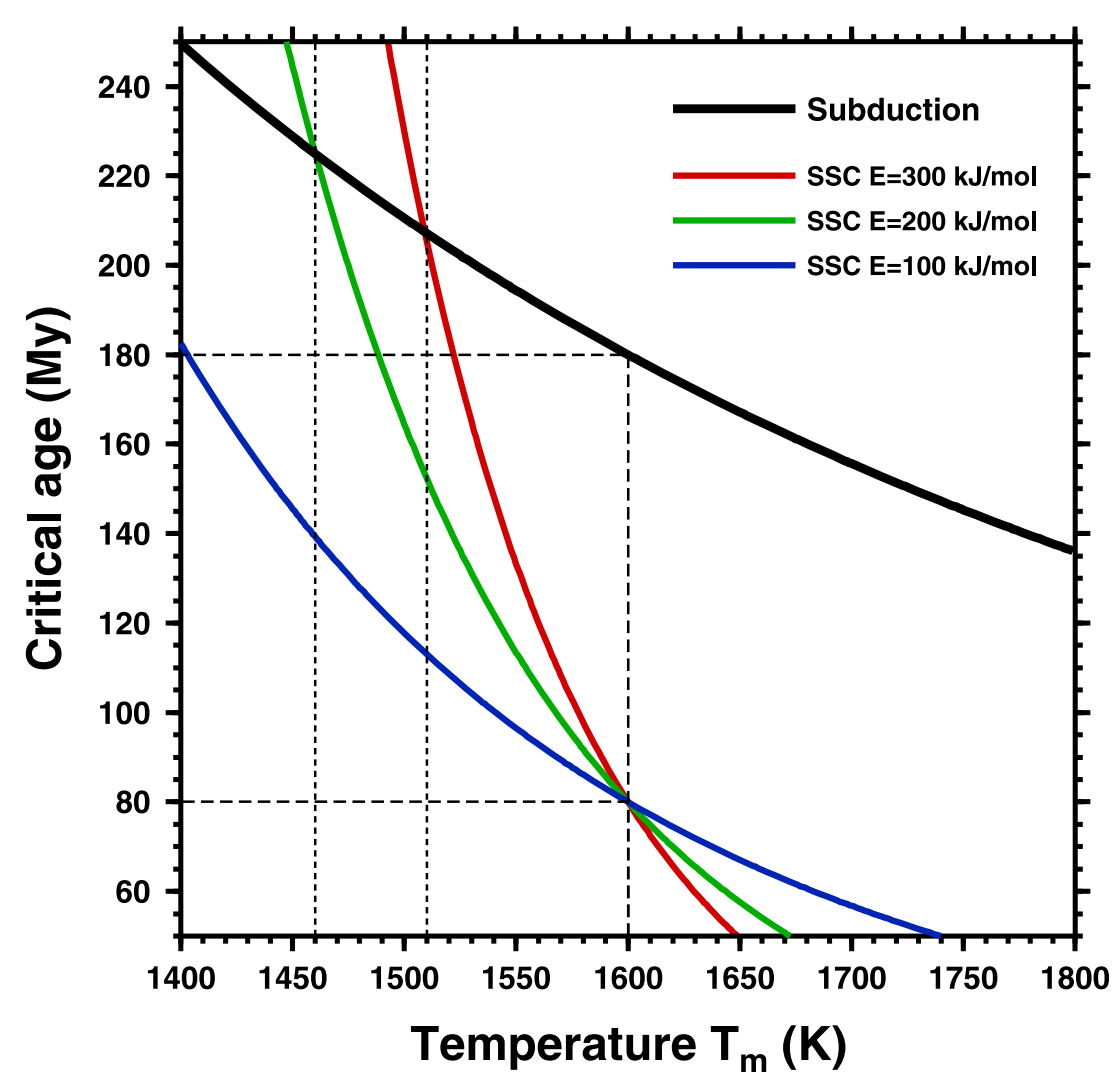

Figure 2. Critical ages for the onset of small scale convection (blue, green and red curves) and for subduction initiation (black) as a function of $T_{m}$ and $E$, for a present day temperature $T_{m}^{p}=1600 \mathrm{~K}$.

on Earth is still debated [e.g., Gerya et al., 2008], subduction zones can be explicitly imposed as being one-sided with our multiagent approach, the overriding plate being the younger. Similarly, the relationship between deformation regime in subduction zones and trench kinematics is a complex issue [e.g., Heuret and Lallemand, 2005; Heuret et al., 2007]. We therefore assume a simple rule for trench migration that accounts for both compressive and extensive regimes in the upper plate, following a structural criterion presented in Figure 3. Here at subduction initiation, the trench moves horizontally with the velocity of the younger plate, except when an extensive structure arises in the simulation. Indeed, a back-arc basin formation occurs in this case, by creating a ridge between the trench and the upper plate. Figure 3a displays the compressive case that assigns $V_{t}=V_{u p}$ in our model, whereas the two cases described in Figures $3 \mathrm{~b}$ and $3 \mathrm{c}$ illustrate extensive contexts. In the latter cases, a ridge is created, leading to a new compressive structure near the trench, and consequently $V_{t}=V_{u p}$. Considering both extensive and compressive regimes allows us to account for back-arc spreading zones, which rejuvenates the sea floor in the manner observed on the Western Pacific coast.
[22] Ridges are also mobile in our model, and conservation of Earth's perimeter prescribes their velocities $V_{r}$. Assuming symmetric spreading, the motion of the ridge that separates plates A and B is

$$
V_{r}=\frac{U_{A}+U_{B}}{2}
$$

where $U_{A}$ and $U_{B}$ are the respective velocities of plates $\mathrm{A}$ and $\mathrm{B}$, which ultimately result from the force balance on the plates. Note that since plate boundaries are mobile, mid-ocean ridges can be subducted. In this case, both the slab and the ridge are removed from the system, and the upper plate becomes sutured to an oceanic plate section with age zero.

[23] Plate suturing occurs when a subduction zone consumes a ridge, or when a back-arc basin is created above a subduction zone, causing the upper plate to suture with the newly-formed oceanic section (the suture is indicated by a black circle on Figures 3 and 4. In two dimensions, Earth's surface always displays alternatively ridges and subduction zones, since two adjacent cells must rotate in opposite directions. This may lead to the transient 


\section{a) Compression}

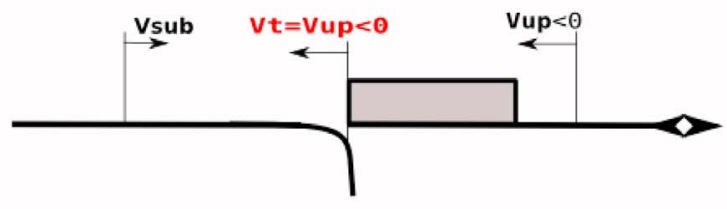

b) Spontaneous lower plate sinking

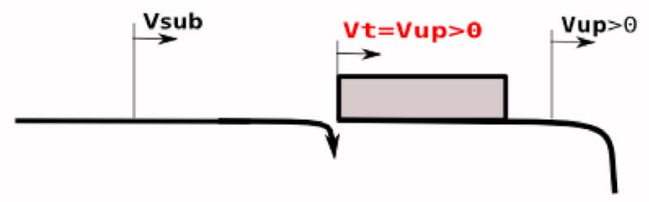

c) Spontaneous upper plate sinking

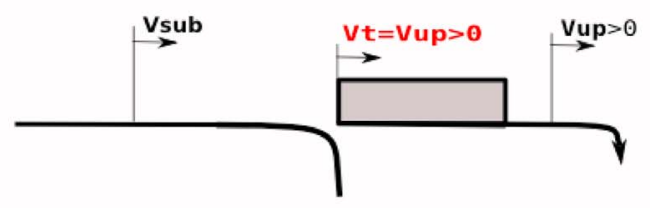

d) Resulting ridge creation : roll back

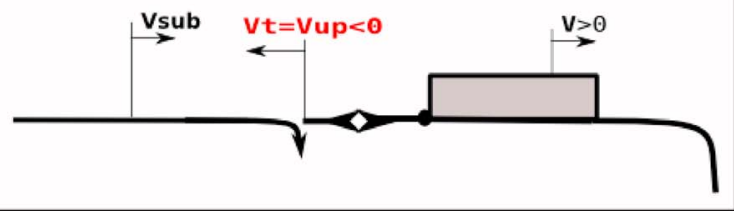

Figure 3. Structural criterion for the trench migration process in various contexts (the direction of subduction is defined as positive for all velocities). (a) When the upper plate is driven by ridge push, we assume a compressive regime and trench migration is subsequently prescribed by the upper plate motion: $V_{t}=V_{u p}$. When the upper plate is driven by a slab pull, we assume an extensive regime, and a new ridge is created: this occurs for subduction initiation of (b) the lower plate or (c) the upper plate. (d) In both cases, a ridge is created and the trench undergoes a roll back motion. This structural criterion is independent of continents, presented here in grey.

existence of extremely low aspect ratio cells (e.g., Figures 4a1 and 4a2). Alternatively, one plate may cover several cells, as illustrated in Figures $4 b 1$ and $4 \mathrm{~b} 2$.

\subsection{Adding Continents}

[24] Our model may be used with or without continents. Continental lids are defined by the user in the initial state and thus define the continental plate sections. As a first approximation, our model assumes perfectly insulating continents, and the surface heat flux (equation (3)) is integrated through oceanic lithosphere only (equation (2)). The inclusion of continents requires a few additional empirical laws concerning subduction processes, plate suturing, and thermal behavior of the system.

[25] Continents are fixed upon the moving plates, and cannot sink. Consequently, when a buoyant lid reaches a plate edge, the corresponding slab detaches, and the border of the lid coincides with the plate boundary. If the adjacent sea floor of the ancient overriding plate is older than $180 \mathrm{Myr}$ (for current Earth), the oceanic plate instantaneously subducts. Otherwise the two plates are sutured without altering the age distribution (Figure 4). Note that the continental distribution may strongly impact the sea floor age distribution: depending on the force balance and the resulting plate velocities, sea floor sections younger than $180 \mathrm{Myr}$ can subduct, which may cause non-rectangular sea floor age distributions [Labrosse and Jaupart, 2007].

[26] In case of continental collision, a larger continent is created, which can be followed by shallow temperature elevation and continental breakup (Figure 5). Indeed, our model incorporates a semiempirical process that allows for mid-oceanic ridge creation, which is needed to allow for the emergence of continental cycles. We propose here a simplified oceanization mechanism based on heat advection beneath insulating continents. Insulating lids with internal radiogenic heating induce shallow temperature elevation in the underlying mantle [Coltice et al., 2007; O'Neill et al., 2009; Phillips and Coltice, 2010], and we propose an analytical formulation of the threshold advection velocity corresponding to continental breakup.

[27] Our simplified parameterization accounts for the warming and subsequent advection of a shallow fluid layer of depth $h$, below continents of width $a$. Considering the equations for the conservation of mass, momentum and energy in the advection layer, and assuming a uniform temperature before supercontinental aggregation, we obtain a linear relation between the average fluid velocity and the following time-dependent temperature $T_{h}(t)$ of the advection layer (see auxiliary material):

$$
T_{h}(t)=T_{h}^{o}+T_{c}\left(1-\frac{2}{1+\exp \left(2 T_{c} \cdot \gamma \cdot t\right)}\right)
$$

where $T_{h}^{o}$ is the temperature before aggregation and $T_{c}$ is the maximum temperature elevation that can be reached beneath the continent. $T_{c}$ is a function 

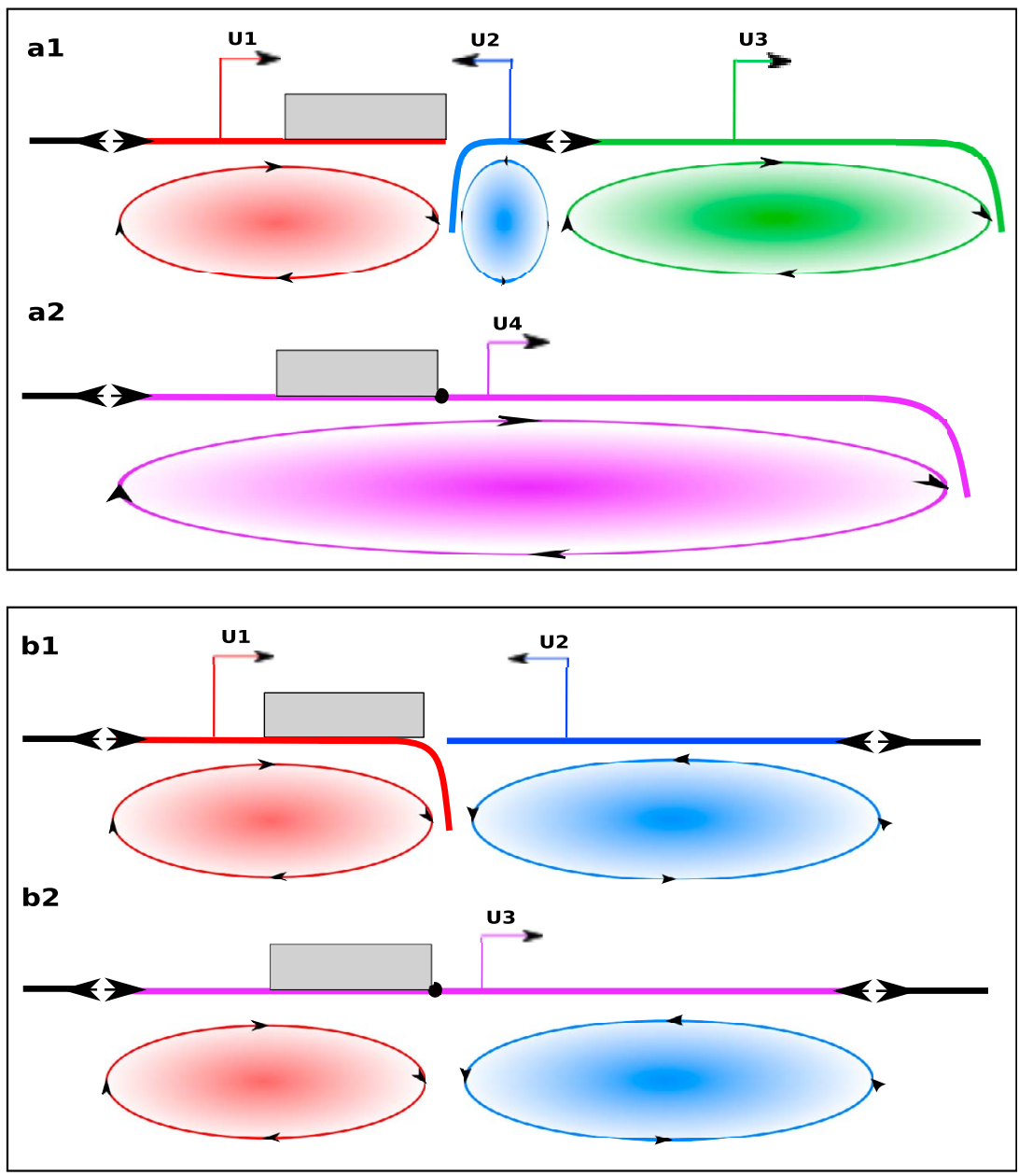

Figure 4. (top) Plate suturing process due to the arrival, and subsequent removal, (a1) of a ridge at a subduction zone. (a2) In this case, the two remaining plates are instantaneously sutured and the underlying identical cells merge. A staple (black circle) indicates the location of the sea floor age discontinuity. (bottom) Continent arrival at the extremity of a plate. When a continent abuts on another plate, it gives rise to a suturing process. (b1) First, slab detachment occurs and slab pull vanishes. (b2) Then, either the opposite plate sinks if it is older than $\tau_{\text {subd }}$, or the two plates are sutured if they cannot sink.

of internal heating rate $Q_{\text {radio, }}$, mantle density $\rho_{m}$, thermal capacity $C_{p}$, and a quantity $\gamma$ that accounts for the layer geometry:

$$
\begin{gathered}
T_{c}=\sqrt{\frac{Q_{\text {radio }}}{\rho_{u m} C_{p} \gamma}} \\
\gamma=\frac{2 h \alpha \rho_{u m} g}{\eta_{u m}\left(\left(\frac{a}{2 h}\right)^{-2}+\left(\frac{a}{2 h}\right)^{2}\right)}
\end{gathered}
$$

[28] Assuming a yield force $F_{\text {lim }}$ for the brittle continent, we consider that oceanization occurs when the advection velocity $U_{h}$ reaches the corresponding critical velocity. That threshold corresponds to an advection shear force equal to $F_{\text {lim. }}$. In this case, a mid-oceanic ridge is created in the middle of the lid, and the two new lithospheric plates undergo a growing ridge push force. This oceanization process occurs only when the supercontinent is bounded by two subduction zones. A passive margin on one edge of the continent would otherwise imply that the newly created ridge, with a very low ridge push force RP (equation (5)) due to $\tau_{s} \simeq 0$ would compete with a higher RP force coming from the adjacent plate, yielding the instant reclosure of the continent.

[29] Our advection mechanism allows for warming durations before opening that are within an order of magnitude of accepted values for supercontinental breakup during the thermal history of the Earth [ $\mathrm{Li}$ et al., 2008] for large continents (100-300 My), and no possible opening for narrow continents (less 


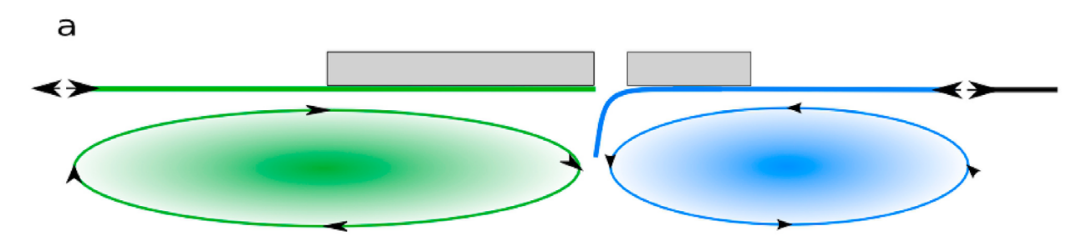

b
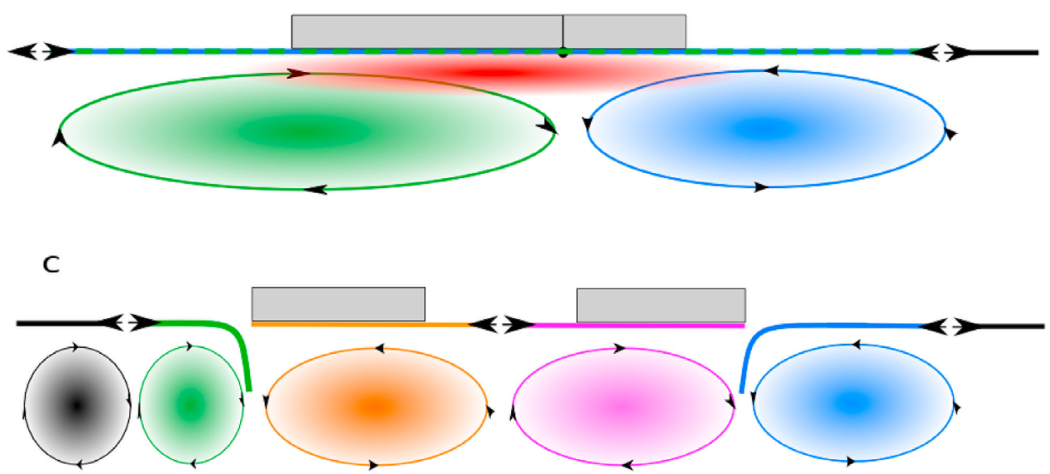

Figure 5. Supercontinent aggregation followed by continental breakup and ocean opening. Continental collision leads to (a) slab detachment and (b) temperature elevation in the shallow advection layer. (c) Once the shear force exceeds the yield force, the continent breaks up and a new ocean opens.

than $6000 \mathrm{~km}$ wide). A specific study on the choice of $F_{\text {lim }}$ and $h$ is proposed in the auxiliary material.

\section{Mimicking Earth's Tectonics}

[30] The MACMA model has been tested over three timescales. First, we benchmark the model by comparing instantaneous solutions to plate kinematics. Secondly, we investigate the impact of various viscosity profiles on plate tectonics and heat flux evolution over 300 million years. Finally, the role of two behavior laws on the thermal evolution of the Earth over 3 Gyr is explored: (i) subduction initiation process and (ii) continental dynamics related to mantle rheology.

\subsection{Plate Kinematics}

[31] Our goal is to simulate credible plate tectonics that accounts for a variety of phenomena observed on Earth, such as mobile plate boundaries, timedependent plate and margin velocities, and the influence of subduction history on plate motions. Our predicted plate velocities for the four Earth-like plates displayed in Table 2 are in good agreement with terrestrial plate motions in the No-Net-Rotation (NNR) reference frame [DeMets et al., 1994], which best compares to our model setup. We observe that slab pull is a prominent control on plate velocities in the Pacific basin, and that mantle drag implies a lower velocity for the Pacific $(4.3 \mathrm{~cm} / \mathrm{yr})$ than for the Nazca plate $(7.0 \mathrm{~cm} / \mathrm{yr})$ because the former is wider, which renders the integrated resisting shear force higher. This force balance accounts for slab suction, that is responsible for the motion of South America $(0.9 \mathrm{~cm} / \mathrm{yr})$ and Africa $(1.5 \mathrm{~cm} / \mathrm{yr})$. It can also be noted that slab pull and slab suction are globally counterbalanced by mantle drag, as suggested by Carlson [1983]:

$$
S P+S S+M D \simeq 0
$$

In our model, plate kinematics efficiently respond to structural changes (Figure 6): the motion of a plate that mimics the South American plate varies in a plausible fashion as plates are redefined at every structural change: the spontaneous subduction initiation at 31 Myr implies a velocity drop because slab suction vanishes (the plate is no longer pulled by the Nazca slab), but the development of a secondary slab pull after $31 \mathrm{Myr}$ allows the plate velocity to increase until $45 \mathrm{Myr}$, when slab pull becomes steady. Plate velocity varies continuously when the slab enters the lower mantle at $45 \mathrm{Myr}$, because slab pull in the lower mantle is replaced by slab suction. This experiment demonstrates that our force balance allows for plate tectonic timedependence that accounts for subduction history.

\subsection{Interplay Between Tectonics and Heat}

[32] The dynamic evolution of plate velocities on Earth implies significant fluctuations in the sea floor age distribution [Labrosse and Jaupart, 2007], a 
Table 2. Average Plate Velocity $U(\mathrm{~cm} / \mathrm{yr})$ and Driving Force Strengths Computed for Four Earth-Like Plates, Compared With Plate Velocities in NNR [DeMets et al., 1994] ${ }^{\mathrm{a}}$

\begin{tabular}{lcccc}
\hline & NZ & P & SA & A \\
\hline $\mathrm{L}(\mathrm{km})$ & 3900 & 8000 & 6000 & 7700 \\
$\tau(\mathrm{Myr})$ & 51 & $\geq 80$ & $\geq 80$ & $\geq 80$ \\
$\mathrm{Z}(\mathrm{km})$ & 1200 & 1200 & 1200 & 1600 \\
$\mathrm{RP}\left(10^{12} \mathrm{~N} / \mathrm{m}\right)$ & 1.7 & 2.7 & 2.7 & 2.7 \\
$\mathrm{SP}\left(10^{12} \mathrm{~N} / \mathrm{m}\right)$ & 32 & 40 & 0 & 0 \\
$\mathrm{~B}\left(10^{12} \mathrm{~N} / \mathrm{m}\right)$ & 0.9 & 1.1 & 0 & 0 \\
$\mathrm{MD}\left(10^{12} \mathrm{~N} / \mathrm{m}\right)$ & 36 & 45 & 6.8 & 14.7 \\
$\mathrm{VS}\left(10^{12} \mathrm{~N} / \mathrm{m}\right)$ & 1.0 & 0.6 & 0 & 0 \\
$\mathrm{SS}\left(10^{12} \mathrm{~N} / \mathrm{m}\right)$ & 4.2 & 4.2 & 4.2 & 12 \\
$\mathrm{U}(\mathrm{cm} / \mathrm{yr})$ & 7.0 & 4.3 & 0.9 & 1.5 \\
$\mathrm{NNR}(\mathrm{cm} / \mathrm{yr})$ & 7.4 & 6.3 & 1.1 & 2.8 \\
\hline
\end{tabular}

${ }^{\mathrm{a}}$ Each plate is characterized by its length $L$, subduction age $\tau$ [Forsyth and Uyeda, 1975; Conrad and Hager, 1999a], slab depth $Z$ [e.g., Replumaz et al., 2004], and the nature of its boundaries. NZ: Nazca, P: Pacific, SA: South America, A: Africa.

process that is neglected in most models because they do not account for evolutive plate boundaries.

[33] Figure 7 shows two sea floor age distributions obtained at $79 \mathrm{Myr}$ and $287 \mathrm{Myr}$ for an experiment starting with a thermal state, viscosity structure and continental distribution representing present day. The first distribution is almost triangular, meaning that subduction occurs at all ages with the same probability, as observed on present-day Earth [Parsons, 1982; Rowley, 2002]. Such a sea floor age distribution occurs when "several spreading systems become active at different times and compete for space" [Labrosse and Jaupart, 2007]. These authors show that a triangular distribution can be obtained if spreading zones are not parallel to subduction zones -a setting that we cannot treat in our 2D model- but they also emphasize the fact that triangular distributions may occur if several plate boundaries do not have the same dynamics, which is the case in two dimensions. Conversely, the rectangular distribution at $287 \mathrm{Myr}$ means that subduction occurs preferentially at old ages (Figure $7 b$ ). Fluctuations in the sea floor age distribution emerge in our simulations because all plates dynamically compete for space, and the system consequently evolves between homogeneous and heterogeneous cell lengths and subduction ages. Such important fluctuations are illustrated on Earth by the timedependent heat flux derived from tectonic reconstructions during the Cenozoic [Becker et al., 2009], which suggests that Earth's current sea floor age distribution is a snapshot within a transient regime.
[34] The heat flow evolves accordingly (Figure 8). Note that Earth's total heat loss should also include 14 TW coming out of continents [Jaupart et al., 2007]. A triangular sea floor age distribution corresponds to a higher heat flow (42.0 TW) than a rectangular distribution (30.4 TW), reflecting the higher proportion of young sea floor when subduction occurs at all ages with the same probability. Labrosse and Jaupart [2007] propose a simple heat flux parameterization based on the sea floor age distribution:

$$
Q_{L J 07}(t)=\frac{\lambda(t) S_{o c} k\left(T_{m}(t)-T_{0}\right)}{\sqrt{\pi \kappa \tau_{\max }(t)}}
$$

where $\tau_{\max }$ is the maximum sea floor age at a given time $t$, and $\lambda$ is an age distribution factor, equal to $8 / 3$ for a triangular distribution and 2 for a rectangular distribution. This equation predicts oceanic heat flows of $45.4 \mathrm{TW}$ and $34.0 \mathrm{TW}$, respectively, which are only $8 \%$ and $11 \%$ different from our model predictions, reflecting the approximation of perfectly triangular and rectangular distributions in the parameterized model. Our results confirm the relevance of the empirical parameterization (equation (20)) and thereby emphasize the importance of accounting for the changing sea floor age distribution when studying the thermal evolution of the mantle. This is particularly important when constraining thermal history using Earth's present day heat loss, because even a small change in the sea floor age distribution may imply important consequences on the thermal state of the mantle in the past [Grigné et al., 2005; Labrosse and Jaupart, 2007].

[35] The short-term evolution of oceanic heat flow emerges from the global subduction history, as well as the sea floor age distribution. Using our initial setting, which is a $2 \mathrm{D}$ representation of the present day plate configuration, we observe a current decrease in the global heat flow (Figure 8), as suggested by the sea floor age reconstructions of Loyd et al. [2007] and Becker et al. [2009]. Longterm studies by Grigné et al. [2005] and Labrosse and Jaupart [2007] incorporate such fluctuations in their model by assigning periodic variations in the convection wavelength and age distribution factor, respectively, which highlights the strong dependence of oceanic heat flux on short-term plate tectonics. In our model, such a dependence instead emerges from local tectonic processes within a global competition for space. 


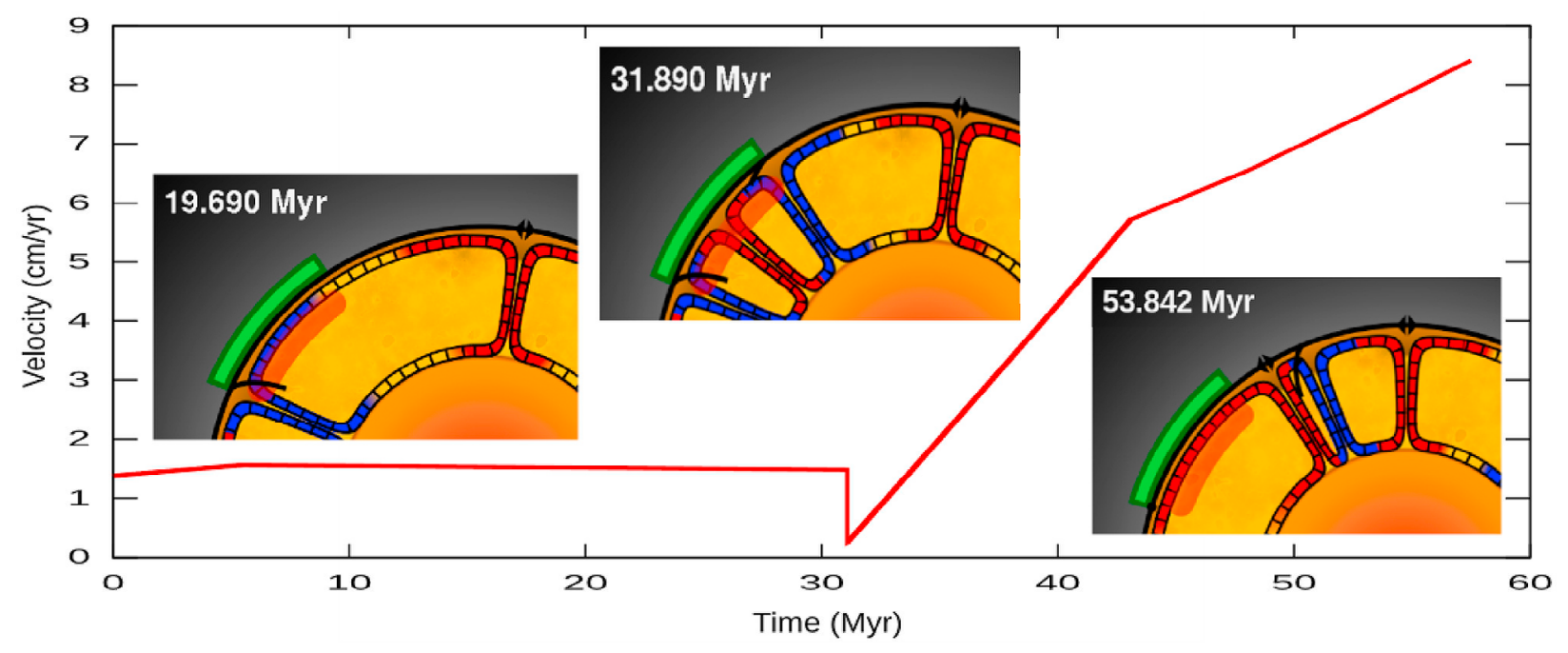

Figure 6. Plate velocity evolution due to structure changes over $60 \mathrm{Myr}$.

[36] In a second experiment, we compare the previous results to those corresponding to lower imposed viscosities: $\eta_{m}^{p}=10^{21}$ Pa.s in the lower mantle, and $\eta_{u m}^{p}=10^{20}$ Pa.s in the upper mantle. Lower viscosities cause heat flow and average velocity variations with shorter timescales and up to $100 \%$ larger amplitudes (Figure 9). These changes occur because the mantle viscosity affects the average strain rate: total momentum conservation keeps mantle drag equivalent to slab pull and slab suction (equation (19)) which do not depend on evolutive mantle viscosity, but only on its imposed presentday value (equations (7), (11), and (12)). Thus, the lower this viscosity, the higher the strain rate. Kinematics are thus significantly affected: in the low viscosity case, the average plate velocity is almost three times higher than for current mantle (Figure 9). The velocity variation timescale is also shorter for lower viscosities, illustrating greater convective vigor. This effect modifies plate kinematics and leads to a modified sea floor age distribution. As a consequence, with lower viscosities, heat flow would be increasing at present day (Figure 9, blue curve).

[37] Note that plate velocity $U$, derived from equation (4), reaches high values for short plate lengths $L$ because mantle drag can only balance the (non-zero) driving forces on a plate if $U$ increases inversely as $L$ decreases (equation (9)). Even though very short plates may become fast, very high peaks in the average velocity are temporary and have little effect on long term averages.
[38] One important point is that the time-averaged values for plate velocity and surface heat flow over $300 \mathrm{My}$ are not correlated: reducing the mantle viscosity by an order of magnitude causes a 3-fold increase in average plate velocity $(2.7$ to $9.2 \mathrm{~cm} / \mathrm{y})$, but almost no change in average heat flow (37.1 to 37.9 TW), suggesting that in our model, mantle viscosity does not exert a significant impact on long-term averaged heat flux. The evolution of average plate length displayed in Figure 9 shows that this effect comes from the difficulty for a low viscosity fluid to produce stresses sufficient to break the continental lithosphere. As continental rifting and oceanization are the main processes in our model to create ridges and narrow young plates, unbreakable continents imply statistically fewer plates, and thus a large mean plate length. With a low viscosity, plate tectonics is fast, but heat flow does not increase because rejuvenation is impeded by the low viscosity of the subcontinental mantle. Such a decorrelation between time-averaged plate velocity and surface heat flow may have a significant impact on long-term thermal evolution of the system, which will be studied hereafter.

\subsection{Comparison to Numerical Models}

[39] As noted above, we observe an important effect of plate geometry on oceanic heat flux. This effect can be compared to what is obtained in convection simulations that incorporate evolutive plate boundaries [e.g., Gait and Lowman, 2007; Gait et al., 2008; Lowman et al., 2008; Stein and Lowman, 2010]. At first order, similar observations can be 
a)
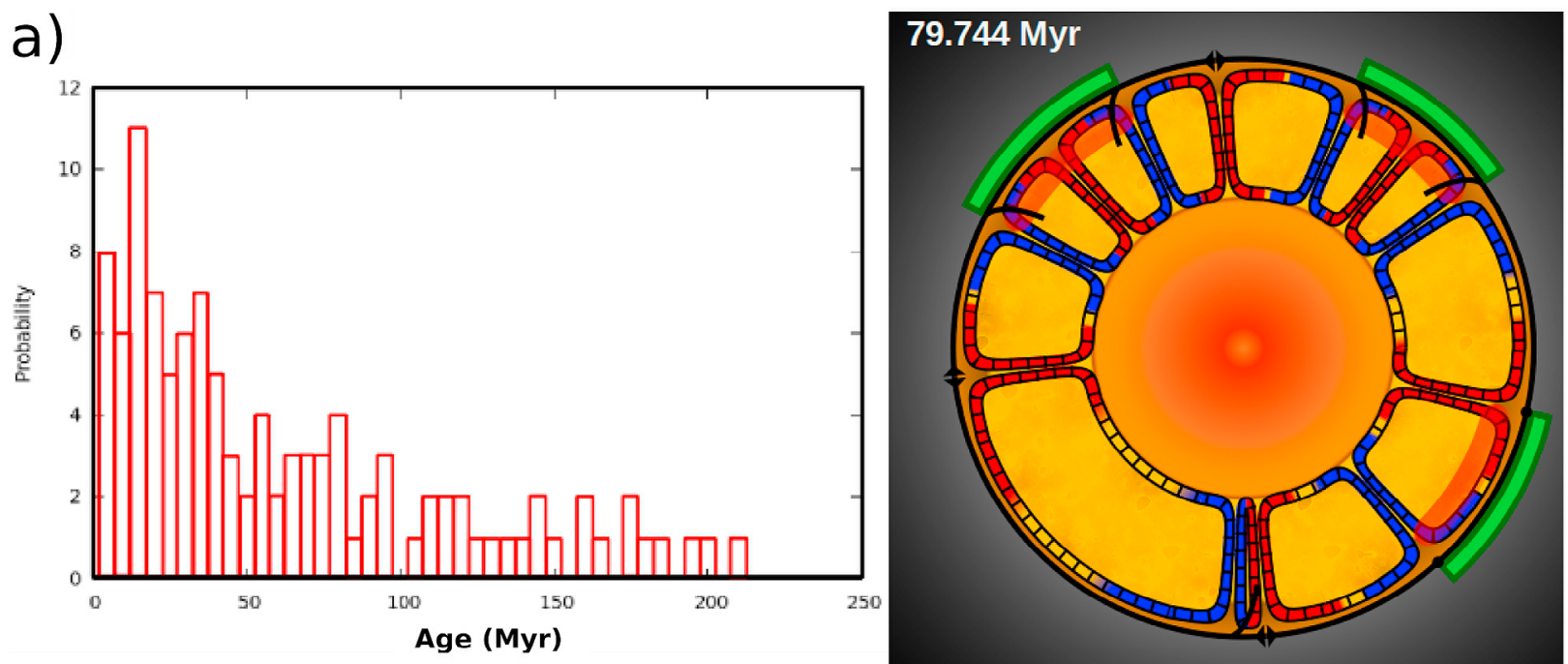

b)
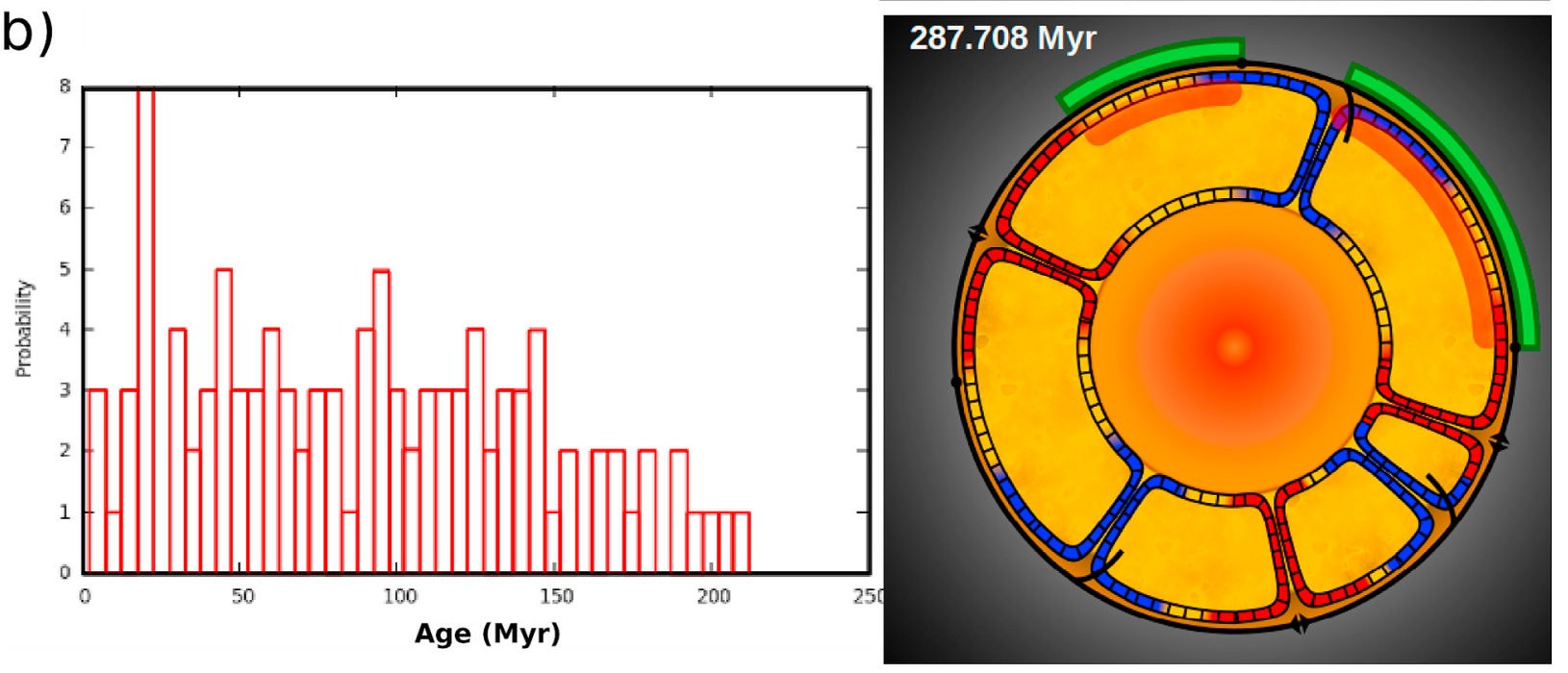

Figure 7. Sea floor age distributions at two different times. Initial state corresponds to present-day. $F_{\text {lim }}=10^{13} \mathrm{~N} \cdot \mathrm{m}^{-1}$ and $E=200 \mathrm{~kJ} \cdot \mathrm{mol}^{-1}$. (a) Triangular and (b) rectangular age distributions.

made: for example, Stein and Lowman [2010] note that heat loss decreases as average plate length increases. We obtain a similar effect: rectangular sea floor age distributions are accompanied by reduced oceanic heat flux in our model. Indeed, the greater proportion of old sea floor in rectangular distributions corresponds to wider plates. This phenomenon is also described by the semi-empirical model proposed by Labrosse and Jaupart [2007]. In addition, we found that the more time-dependent the surface geometry, the shorter the timescale and the greater the amplitude variations in heat flow evolution. This phenomenon is consistent with the results obtained by Gait and Lowman [2007], which show that mobile plate boundaries imply enhanced heat flux time-dependence and amplitude variation, in comparison with fixed boundaries.

[40] Nevertheless, the mechanisms responsible for heat flux fluctuations in our model are not exactly the same as in previous models. In the simulations proposed by Gait and Lowman [2007], plate thickness is uniform over a plate, and is the same for each plate. In this case, evolutive margins allow for an increase in the variability of the local thermal gradient, which leads to an increased heat flux variability. In our approach, heat loss is controlled by the competition for space and by the velocity contrasts between plates, leading to variable spreading rates and time-dependent young sea floor proportion. Here we consider a uniform temperature in 


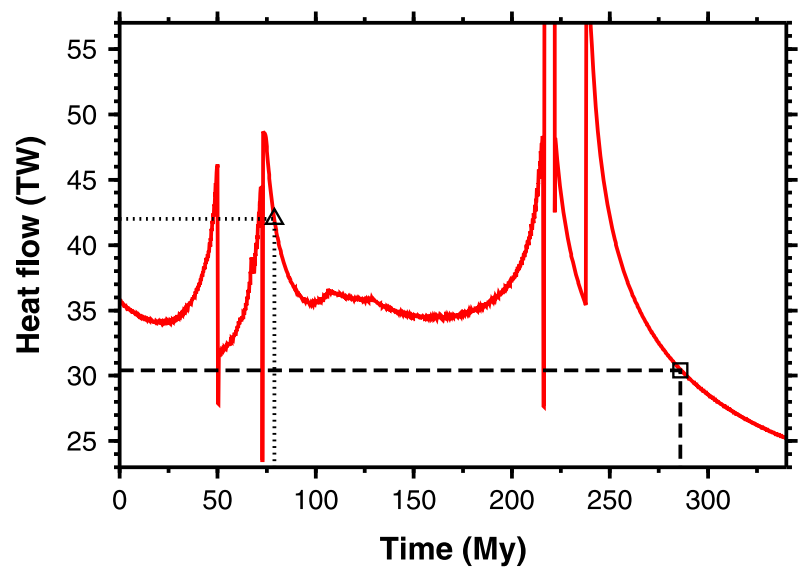

Figure 8. Oceanic heat flow evolution over $340 \mathrm{Myr}$, using present day continent and sea floor age distributions shown in Figure 1 as an initial state, with $\eta_{u m}^{p}=10^{21}$ Pa.s and $\eta_{m}^{p}=10^{22}$ Pa.s. The triangular (dotted line) and rectangular distributions (dashed line) of Figure 8 correspond to $42.0 \mathrm{TW}$ and $30.4 \mathrm{TW}$ at $79 \mathrm{Myr}$ and $287 \mathrm{Myr}$, respectively.

a well-mixed mantle, so heat flow fluctuations arise from the variability in the sea floor age distribution, according to time-dependent plate boundary conditions. This difference explains why we obtain shorter heat flow timescales than models with constant plate thickness.

[41] We can also note that the feedback between mantle temperature and viscosity, via heat loss mechanisms, should be very different in these two models. For uniform plate thickness without continents [Gait and Lowman, 2007], surface heat loss increases as increased mantle temperatures lead to faster plate motions. However, when the sea floor age distribution and continents are accounted for, heat flow becomes controlled by surface processes, whereas plate velocity remains controlled by mantle viscosity and subduction history. Figure 9 provides a clear example of such behavior: heat flow and average plate velocity exhibit identical timescales in our model, but peaks in the heat flow mostly correspond to low velocities (e.g., yellow and orange triangles in Figure 9). This is due to the fact that the sea floor age distribution is modified by structural changes and, in particular, by ridge creations. Young sea floor production enhances heat loss, but, because it results from continental breakup or back-arc basin formation processes that are not driven by slab pull, it is a slow process. Thus, a decrease in the mean velocity may be coeval with an increase in the global heat flow. This phenomenon is illustrated in Figure 9 (blue curve) by the impact of two back-arc basin formations at 63 and $252 \mathrm{Myr}$ (yellow and orange triangles respectively).

\section{Long-Term Thermal Evolution}

[42] Earth's thermal evolution over several billion years is investigated with a specific focus on the role played by essential behavior laws, which control subduction initiation, mantle rheology, and continent dynamics.

\subsection{Subduction Initiation Laws}

[43] We simulate Earth's long-term thermal evolution for three different subduction initiation models: we compare the impact of our brittle criterion (section 2.3, equation (14)) with a convective criterion used by classic scaling laws [e.g.,

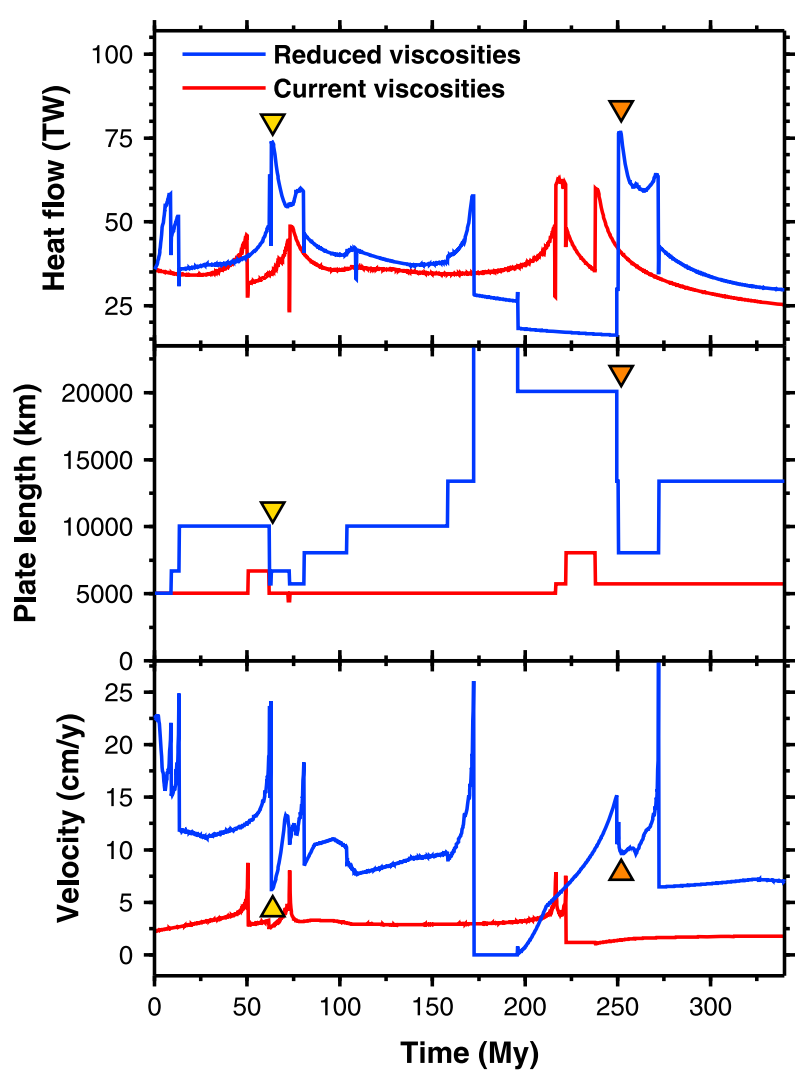

Figure 9. Average plate velocity and length and oceanic heat flow evolution over 300 million years, prescribing the present day as an initial state. The blue lines correspond to $\eta_{u m}=10^{20} \mathrm{~Pa} . \mathrm{s}, \eta_{m}=10^{21} \mathrm{~Pa} . \mathrm{s}$ in the initial state (reduced viscosities), and the red lines to $\eta_{u m}=10^{21} \mathrm{~Pa} . \mathrm{s}$, $\eta_{m}=10^{22}$ Pa.s (current viscosities). Yellow and orange triangles indicate ridge creation events, corresponding to high heat flux values, low average velocities and a decrease in average plate length. 
Christensen, 1985; Turcotte and Schubert, 2002], and also test a constant subduction age $\tau_{\text {subd }}=\tau_{\text {subd }}^{p}$.

[44] The convective criterion states that the oceanic lithosphere remains stable at the surface of the mantle until it reaches a critical thickness, corresponding to a critical Rayleigh number for the thermal boundary layer. The age $\tau_{\text {subd }}$ of such a convective destabilization of the lithosphere at any time on Earth can be written as a function of the present-day one $\tau_{\text {subd }}^{p}$ :

$$
\tau_{\text {subd }}(t)=\tau_{\text {subd }}^{p}\left(\frac{\Delta T_{p}}{\Delta T(t)}\right)^{2 / 3}\left(\frac{\eta\left(T_{m}\right)}{\eta\left(T_{m}^{p}\right)}\right)^{2 / 3}
$$

where the subscript $p$ refers to present-day values, and $\eta\left(T_{m}\right)$ is the temperature-dependent viscosity of the sublithospheric mantle (see auxiliary material for details).

[45] For each case, here and in the next section, the model starts $3000 \mathrm{My}$ ago, and is run forward in time to the present day. The initial temperature of the mantle $T_{m}(t=0)$ is chosen by trial-and-error so that the present-day temperature is $T_{m}^{p}=1600 \pm 10$ (this is possible because the final temperature depends almost linearly on the initial one). The current temperature $T_{m}^{p}=1600 \mathrm{~K}$ is set as the reference state for a viscosity $\eta_{m}\left(T_{m}^{p}\right)=3.10^{22} \mathrm{~Pa} . \mathrm{s}$, which implies that initial viscosities are determined by the activation energy value for each simulation according to equation (1). A maximum oceanic heat flux $q_{\max }=600 \mathrm{~mW} \cdot \mathrm{m}^{-2}$ is set to limit flux above axial zones at ridges, because the half-space cooling model predicts infinite heat flux at the ridge, which is not observed on Earth. Any value of $q_{\max }$ between 400 and $1200 \mathrm{~mW} \cdot \mathrm{m}^{-2}$ does not influence the results (see auxiliary material) and it is thus reasonable to use a constant $q_{\max }$ over time. For the present set of experiments, we chose an activation energy $E=300 \mathrm{~kJ}^{-\mathrm{mol}^{-1}}$ and a continental strength $F_{\text {lim }}=9.10^{12}$ N.m ${ }^{-1}$.

[46] Figure 10 presents thermal evolution solutions and the corresponding age $\tau_{\text {subd }}$ for the three subduction initiation criteria. While the brittle criterion gives a thermal evolution that is almost identical to the constant age case, the convective criterion requires a $40 \mathrm{~K}$ higher initial temperature. This is due to the fact that the convective criterion (equation (21)) yields a low critical age for subduction at high temperatures $\left(25 \mathrm{My}\right.$ for $T_{m}=$ $1840 \mathrm{~K}$ here), implying that old sea floor is easily subducted and tectonic rearrangements are frequent. On the other hand, the brittle criterion (equation (14)) gives a critical age $\tau_{\text {subd }}$ that remains fairly high
(>135 My) throughout the last 3 Gy. Using either criterion or a constant critical age does not seem to influence greatly the global thermal evolution.

[47] Figure 11 shows the total heat flow and mean plate length as a function of time for the three criteria. For the three cases, peaks of heat flow always coincide with steps in the mean plate length evolution: tectonic rearrangements are coeval to young sea floor creation and induce high heat losses. On a timescale of a few hundred million years, an anti-correlation can also be noticed between the mean size of plate and the heat flow. While the constant and brittle criteria give similar results on the long-term, the convective criterion induces a high frequency of changes in the plate length especially over the first half of the experiment. This corresponds to a time-averaged high heat flow and to an efficient mantle cooling, which explains why a higher initial mantle temperature must be fixed.

[48] It is important to note here that the computed critical age $\tau_{\text {subd }}$ does not correspond to the actual maximum age of the lithosphere at any instant of time in our model: since subduction initiation occurs only along passive margins, sea floor older than $\tau_{\text {subd }}$ can be observed along active margins. Therefore, the total heat flow remains limited and we observed no dramatic effect of a low age $\tau_{\text {subd }}$ on the cooling rate.

[49] We also carried out tests for the brittle criterion by varying the present age $\tau_{\text {subd }}^{p}$ between 100 and $260 \mathrm{My}$. As expected, tectonic rearrangements are enhanced for a low value of $\tau_{\text {subd }}^{p}$. As a consequence, the cooling rate increases when $\tau_{\text {subd }}^{p}$ decreases, and in order to obtain a current temperature of $1600 \mathrm{~K}$, an initial temperature $T_{m}(t=0)$ of $1840 \mathrm{~K}, 1800 \mathrm{~K}$ and $1780 \mathrm{~K}$ must be chosen respectively for $\tau_{\text {subd }}^{p}=$ 100,180 and $260 \mathrm{My}$. These three settings correspond to an initial critical age $\tau_{\text {subd }}(t=0)=70$, 135 and $200 \mathrm{My}$, respectively.

[50] We infer from this set of experiments that the choice of the analytical law that describes how $\tau_{\text {subd }}$ depends on $T_{m}$ may be important only if it implies that $\tau_{\text {subd }}$ varies by more than about 50 My around the present-day value. Even though we do not consider the law that we chose (equation (14)) as an actual description of the subduction initiation process, we are confident that our results would be similar with a more accurate law. In conclusion, as far as subduction zones are concerned, the two important laws that control tectonic rearrangements are the behavioral ones that require subduction initiation (1) to be asymmetric and (2) to occur 


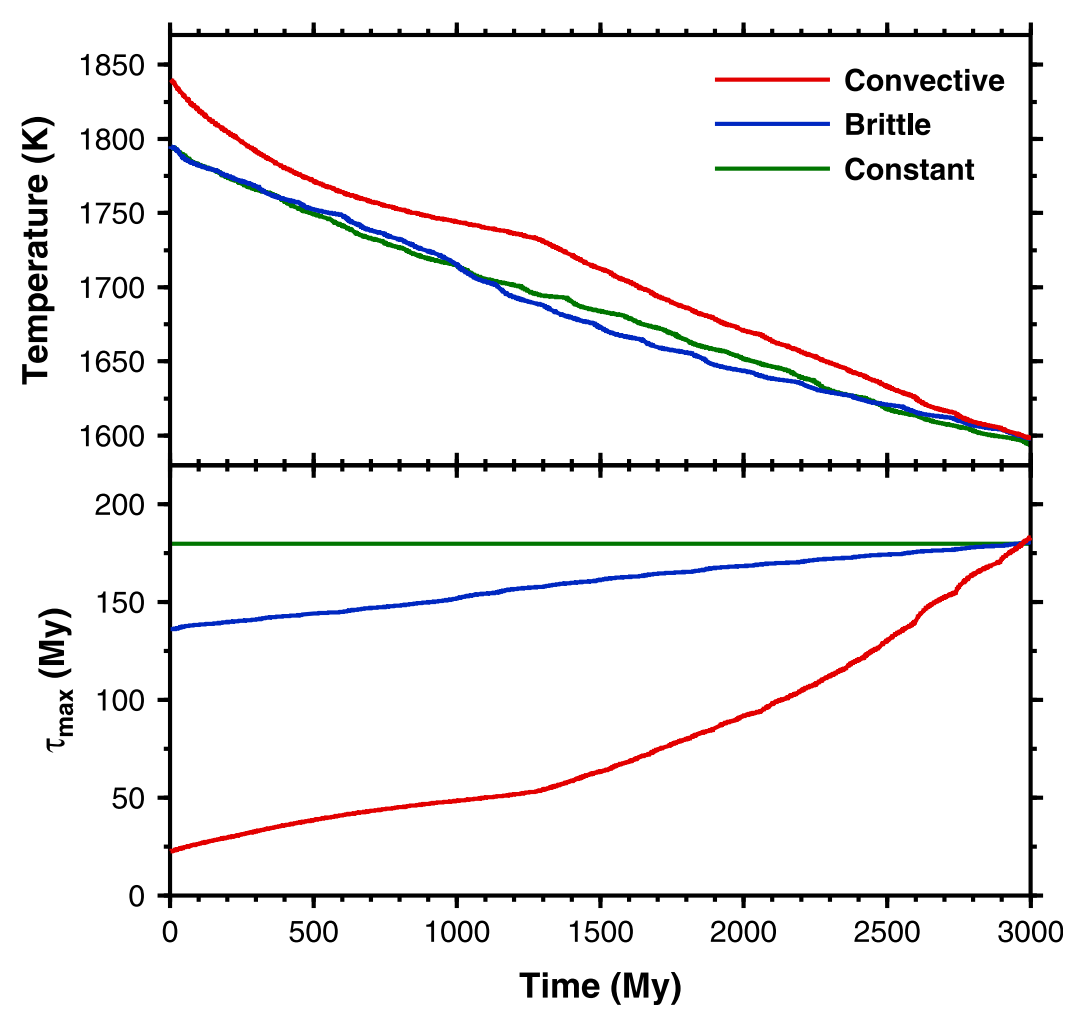

Figure 10. (top) Mantle temperature and (bottom) critical age $\tau_{\text {subd }}$ for subduction as a function of time, with the age of subduction initiation $\tau_{\text {subd }}$ being constant and equal to 180 My (green), or computed with a brittle criterion (equation (14)) (blue) or a convective criterion (equation (21)) (red). Initial temperature is chosen so that $T_{m}^{p}=1600 \mathrm{~K}$. $E=300 \mathrm{~kJ} . \mathrm{mol}^{-1}$ and $F_{\text {lim }}=9.10^{12} \mathrm{~N} \cdot \mathrm{m}^{-1}$.

only along continental margins. The latter could be further investigated if an additional law for oceanocean subduction were implemented here. The first rule is an essential feature of our model: MACMA is set up for modeling terrestrial mantle convection, that is, coupled with plate tectonics and based on field observations. Otherwise, symmetric subduction zones would allow for dramatically decreased maximum sea floor age when using a convective destabilization criterion at high temperatures, since no plate section could be older than this critical subduction age. This would lead to a purely convective fluid behavior, as described by the well known scaling law $\left(N u \sim R a^{1 / 3}\right)$, which corresponds to divergent mantle temperature backward in time [e.g., Davies, 1980; McKenzie and Richter, 1981; Christensen, 1985].

\subsection{Mantle Versus Continental Dynamics}

[51] In our model, plate tectonics depends on both mantle rheology, via the force balance, and continental forcings such as trench migration and ocean opening. Because they may have a significant impact on the sea floor age distribution, and thus on Earth's thermal evolution, the activation energy $E$ and continental yield strength $F_{\text {lim }}$ are therefore key parameters. The former can be viewed as the tuning parameter for mantle rheology, while $F_{\lim }$ characterizes continental dynamics. We herein examine their impact on the mantle thermal evolution with a set of 36 simulations.

[52] Figure 12 shows the evolution of the mean continental width, heat flow and mantle temperature over $3000 \mathrm{My}$, for $E=200 \mathrm{~kJ} / \mathrm{mol}$ with $F_{\text {lim }}$ ranging from $3.10^{12} \mathrm{~N} / \mathrm{m}$ to $9.10^{12} \mathrm{~N} / \mathrm{m}$. As for the preceding experiments, we seek the initial temperature that decreases to its present-day value of $1600 \mathrm{~K}$. This experiment illustrates the mechanism that links $F_{\text {lim }}$ to thermal history: decreasing $F_{\text {lim }}$ makes continental rupture easier, which can be clearly seen in the evolution of the continental size in Figure 12. Indeed, the time-averaged mean size of the continents is respectively 3730,6260 and $7980 \mathrm{~km}$ for $F_{\lim }=3.10^{12}, 6.10^{12}$ and $9.10^{12} \mathrm{~N} / \mathrm{m}$. Subsequent rejuvenation of the sea floor increases the mean heat flow (middle panel in Figure 12) and makes 


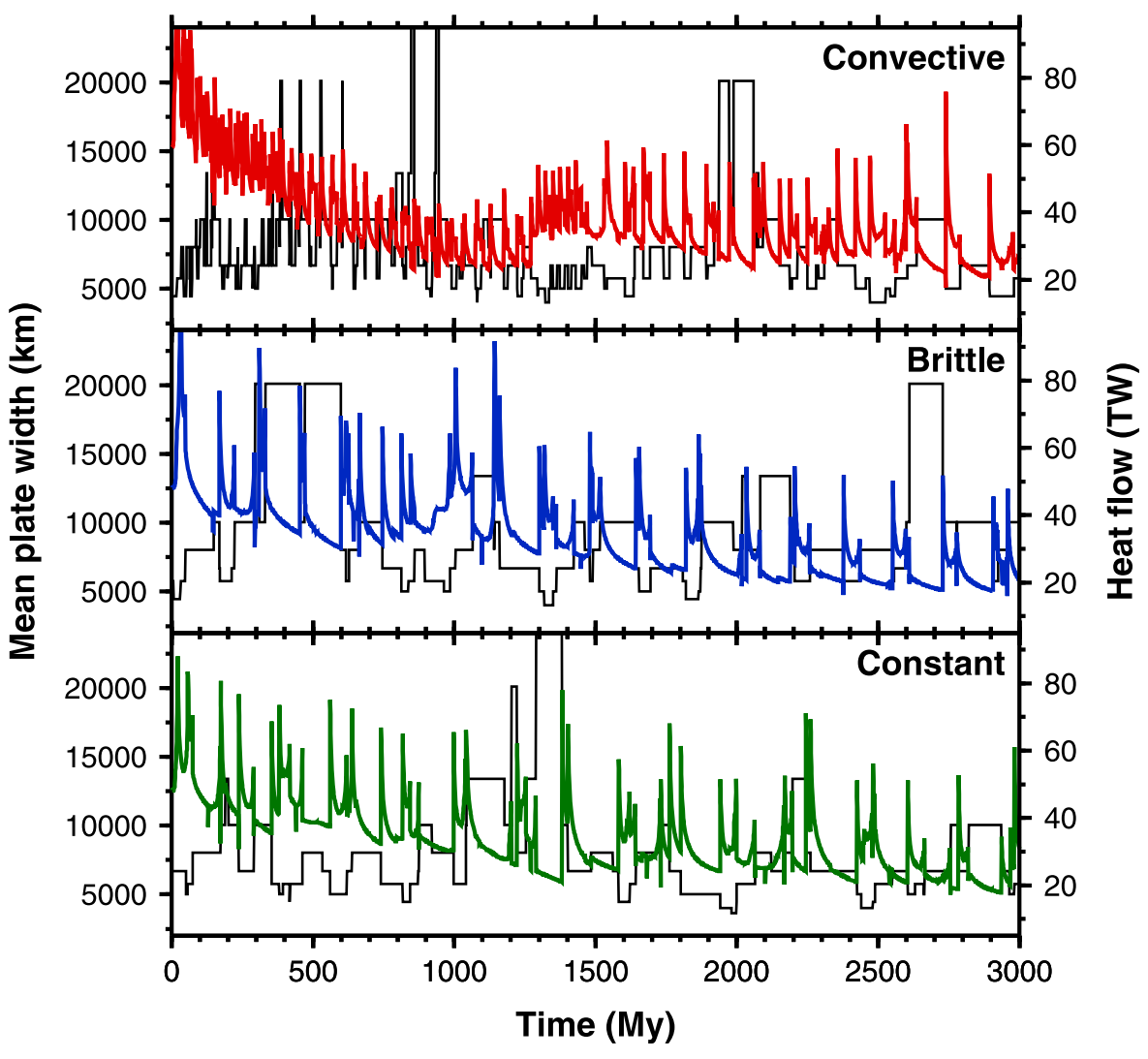

Figure 11. Mean plate length (thin black curves) and total heat flow (colored curves) through time as a function of the subduction initiation criterion for the thermal evolution curves shown in Figure 10.

cooling more efficient, which explains why a higher initial temperature has to be used for a lower $F_{\text {lim. }}$. A second glance reveals that the mean continental size decreases over time and fluctuates more often, particularly for the low $F_{\text {lim }}$ case in Figure 12. This is induced by the decreasing temperature and thus increasing viscosity: shear forces in the subcontinental layer get higher and overcome the fixed strength $F_{\text {lim, }}$, producing smaller continents that break up more often. One example of this process is the threshold effect visible on the red curve of Figure 10: up to $1300 \mathrm{Myr}$, the slope (illustrating the mean heat flux) decreases because increasing mantle viscosity implies reduced spreading rates at ridges, without allowing shear forces to break the continental lithosphere. At $1300 \mathrm{Myr}$, a critical limit is crossed: the viscosity becomes large enough for mantle stresses to break continents into smaller pieces, creating young seafloor. At this point the mean heat flux increases instantaneously.

[53] The combined effects of viscosity and yield stress on plate tectonics are shown in Figures 12 and 13 . For $F_{\lim }=6.10^{12} \mathrm{~N} / \mathrm{m}$ and a low viscosity at
$T_{m} \simeq 1800 \mathrm{~K}$ (star on the orange curve), continent size is much larger than for $F_{\lim }=3.10^{12} \mathrm{~N} / \mathrm{m}$ and a high viscosity at $T_{m} \simeq 1620 \mathrm{~K}$ (blue curve).

[54] While the continental strength $F_{\lim }$ clearly affects the mantle cooling rate, the influence of the activation energy $E$ is small. Figure 14 shows temperature over time for a fixed $F_{\lim }$ and $E$ varying from 0 (constant viscosity case) to $300 \mathrm{~kJ} / \mathrm{mol}$. The larger the activation energy, the larger the viscosity variations. Because the reference at present day is always set to $\eta_{m}\left(T_{m}^{p}\right)=3.10^{22}$ Pa.s, high values of $E$ correspond to low viscosities at the beginning of the simulation. In Figure 14, initial viscosities vary from $8.10^{20}$ to $3.10^{22}$ Pa.s. As expected, a low viscosity yields a high average plate velocity (red curve in Figure 15, compared to black curve), but it also hinders continental breakup and favors long plates. As a result, the seafloor age distribution and thus the overall cooling rate are only slightly affected by the viscosity of the mantle and the activation energy $E$ does not control the thermal evolution of the Earth. 


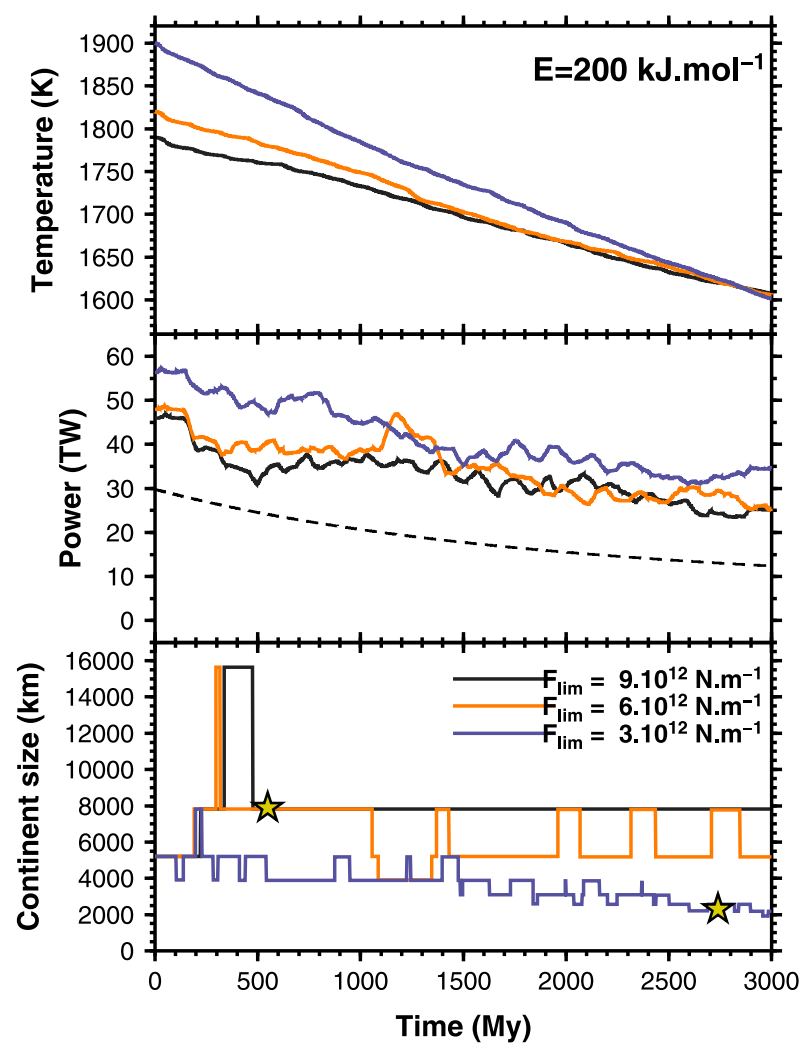

Figure 12. Mean size of the continents, smoothed heat flow, and mantle temperature through time, as a function of the yield stress limit for continents $F_{\text {lim }}$. The dashed black line is radioactive heating. For clarity, heat flows here have been smoothed with a moving average over a bin of $250 \mathrm{My}$. Stars on the orange and the blue curves denote the two configurations of Figure 13.

[55] A synthesis of our parameter space exploration is presented in Figure 16, which shows the average cooling rate over the last $2.5 \mathrm{Gyr}$ as a function of $E$ and $F_{\text {lim. }}$. The latter has an evident impact on the mantle's thermal evolution: higher yield strengths $F_{\text {lim }}$ induce lower cooling rates. However, no hierarchy can be noticed between the curves for different $E$, highlighting the weak influence of $E$ on global heat loss. For high values of $F_{\text {lim }}$, a plateau in the cooling rate is reached, corresponding to no continental breakup. In those cases, the magnitude of the cooling rate chiefly depends on the tectonic history of the system.

\section{Conclusions}

[56] We present a new numerical tool for investigating the coupling between plate tectonics and mantle cooling mechanisms. This model is based on multiagent systems and therefore accounts for both analytical and empirical laws to simulate a variety of processes - even poorly understood ones - that can be introduced and studied independently in a virtual laboratory. The MACMA model computes plate velocities derived from a force balance that accounts for driving forces such as slab pull, ridge push, mantle drag, slab suction and slab bending in two dimensions. Semi-empirical laws are used to describe surface kinematics such as subduction initiation, trench migration or plate suturing. A simplified continental breakup process is also proposed in order to simulate a tectonic system with evolutive plate boundaries and a number of plates that is not fixed. Of course our model assumes a number of important simplifications in order to compute features of the Earth's dynamics over several billion years in few minutes. Therefore, our model should not be viewed as a predicting tool, but as a virtual laboratory that is useful for testing, comparing and modifying physical hypotheses easily. For instance, we have incorporated simple laws for trench migration, subduction initiation and oceanization processes, without considering sophisticated rheologies at continental margins, or magmatic process during continental breakup. Similarly, the rheology of the mantle and continents is still debated, as well as the core cooling dynamics, hence it is useful to have a tool that can help us understand how the Earth works without knowing its precise internal behavior. When available, improved descriptions of these complex processes can be added to the model in the future.

[57] Our dynamic and kinematic laws yield Earthlike plate dynamics, as evidenced by our predicted plate velocities that are in good agreement with observed plate motions. Our model also predicts a heat flow for the present day that is consistent with recent tectonic reconstructions [Loyd et al., 2007; Becker et al., 2009]. Our results highlight the importance of the evolving sea floor age distribution on Earth's thermal history: we find that the competition for space controls the short-term heat flux evolution, confirming the results of the empirical thermal model proposed by Labrosse and Jaupart [2007]. Our study also gives insight into the coupling between time-dependent tectonics and secular cooling, by highlighting the difference between models that consider heat flow fluctuations originating from sea floor age variability, and models in which these fluctuations arise from the evolving mantle temperature distribution. In particular, our simulations suggest that viscosity variations modify plate tectonics and the short-term thermal regime, 

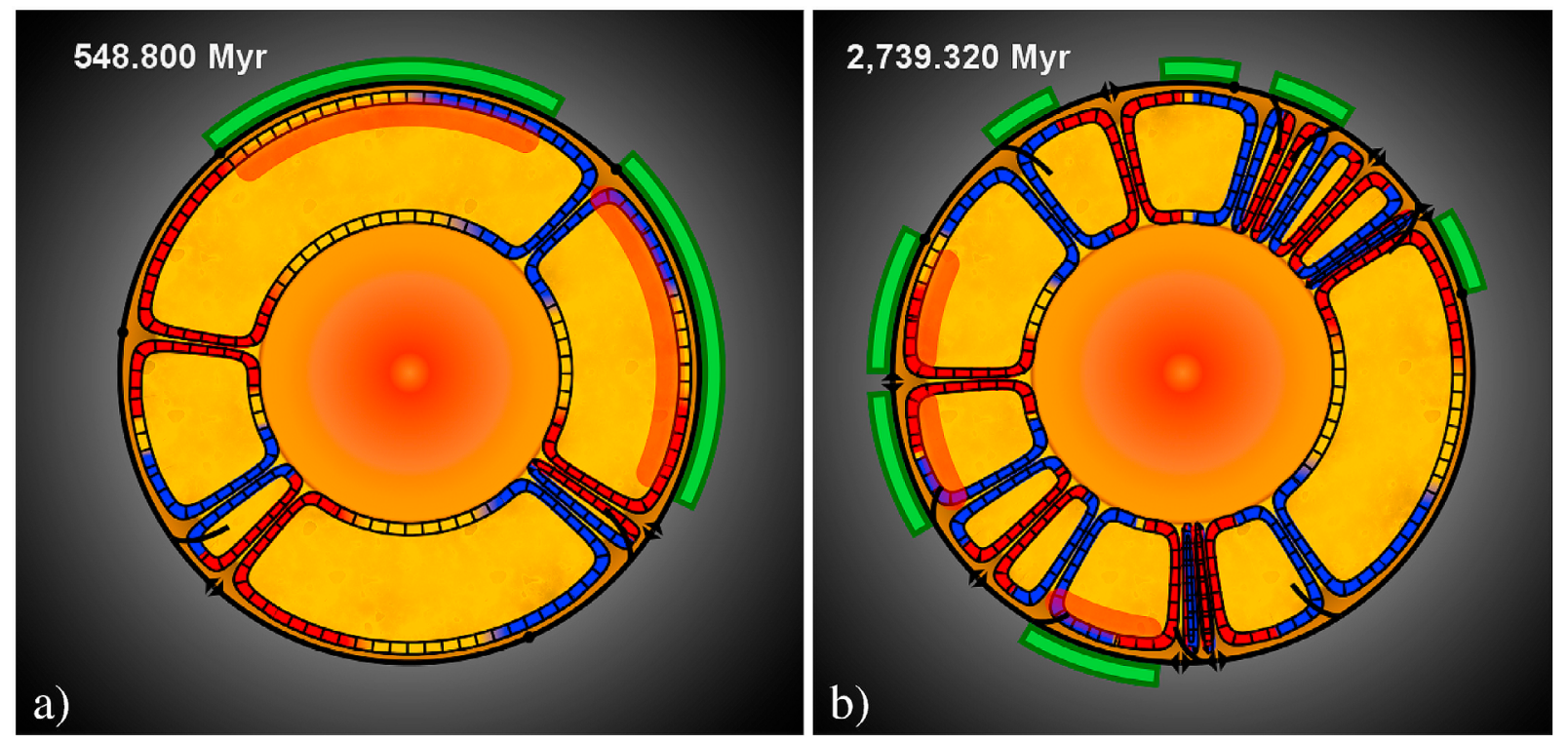

Figure 13. End-member configurations for plate tectonics in the models of Figure 12 (see stars). (a) Large continents and long-wavelength convection are excited by low mantle viscosity $\left(T_{m} \simeq 1800 \mathrm{~K}\right)$ and high continental yield strength $\left(F_{\text {lim }}=6 \cdot 10^{12} \mathrm{~N} / \mathrm{m}\right)$. (b) Small continents and short wavelength convection are induced by high viscosity $\left(T_{m} \simeq 1620 \mathrm{~K}\right)$ and a low value of $F_{\lim }\left(3 \cdot 10^{12} \mathrm{~N} / \mathrm{m}\right)$.

but that the influence of viscosity on Earth's longterm thermal evolution seems minor.

[58] We finally carried out a specific parameter exploration in order to assess the role of behavior laws for processes whose physics are not sufficiently known. In particular, we showed that subduction initiation may have a significant impact on Earth's thermal behavior, and further investigation is needed to quantify the role of the localization of subduction initiation. Then, in order to explore

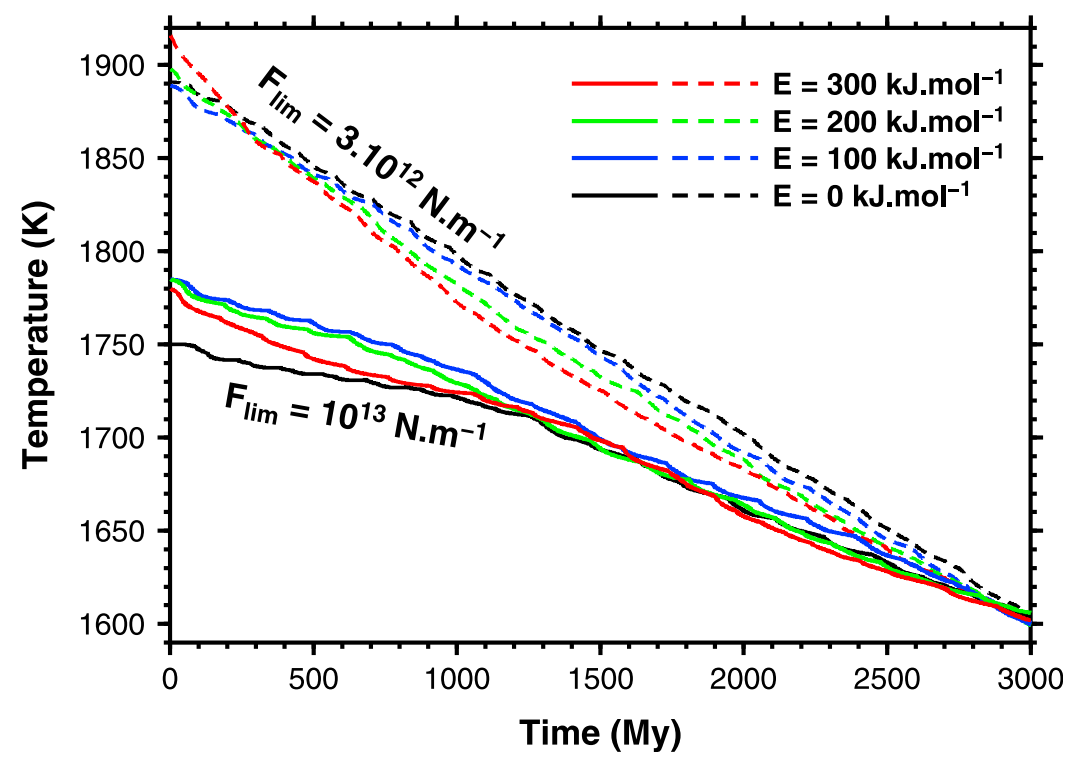

Figure 14. Mantle temperature evolution over $3 \mathrm{Gyr}$, for $E$ ranging from 0 to $300 \mathrm{~kJ} / \mathrm{mol}$, for weak $\left(F_{\text {lim }}=3.10^{12} \mathrm{~N} / \mathrm{m}\right.$, solid curves) and strong continents $\left(F_{\text {lim }}=10^{13} \mathrm{~N} / \mathrm{m}\right.$, dashed curves). 


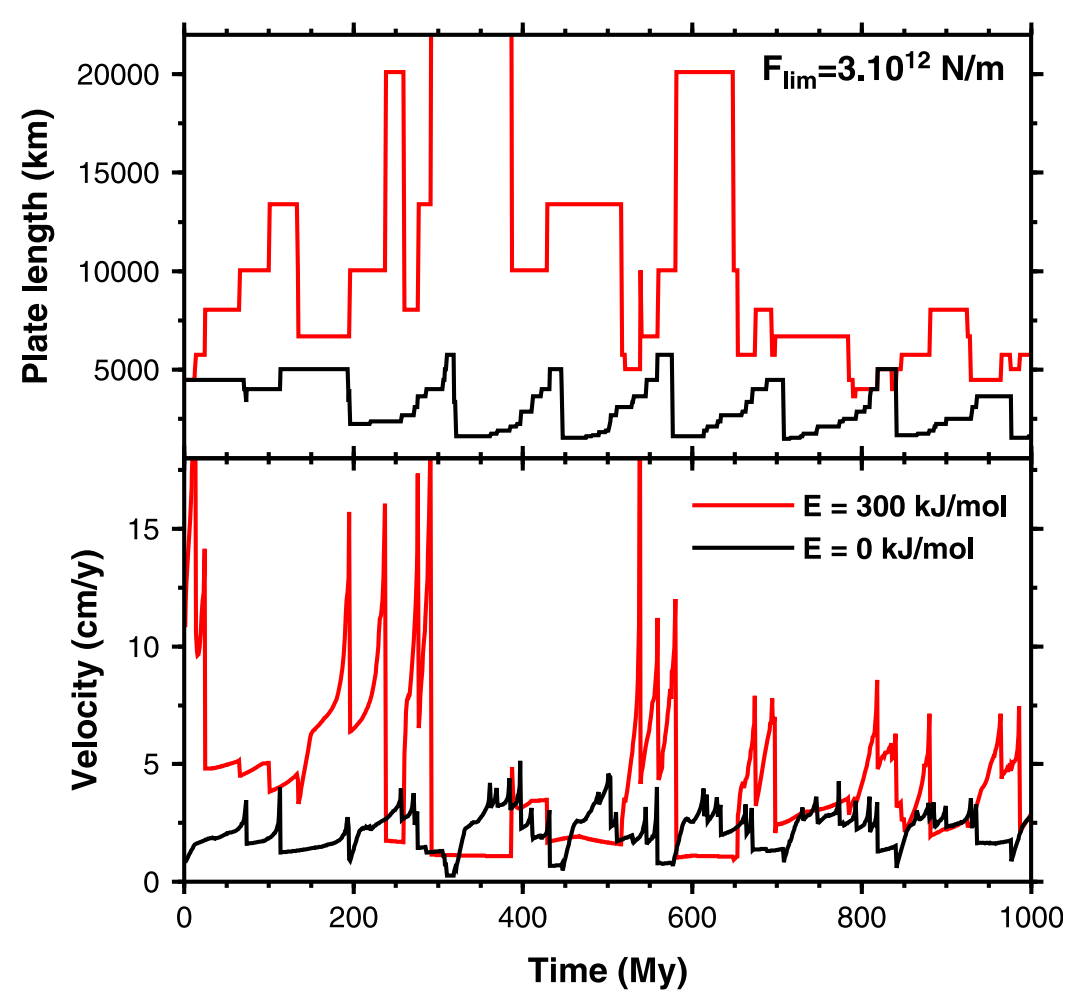

Figure 15. Evolution over $1 \mathrm{~Gy}$ of the average plate velocity and length for $F_{\text {lim }}=3.10^{12} \mathrm{~N} / \mathrm{m}$ and two different activation energies. Initial viscosities are respectively $3.10^{22}$ and $8.10^{20} \mathrm{~Pa} . \mathrm{s}$ for $E=0$ and $E=300 \mathrm{~kJ} / \mathrm{mol}$.

the respective roles of mantle and continental dynamics, we chose activation energy and continental strength as their two prominent controls. In conclusion, we found that for each individual plate, its velocity is mainly controlled by two forces: slab pull and mantle drag, that is to say it mainly depends

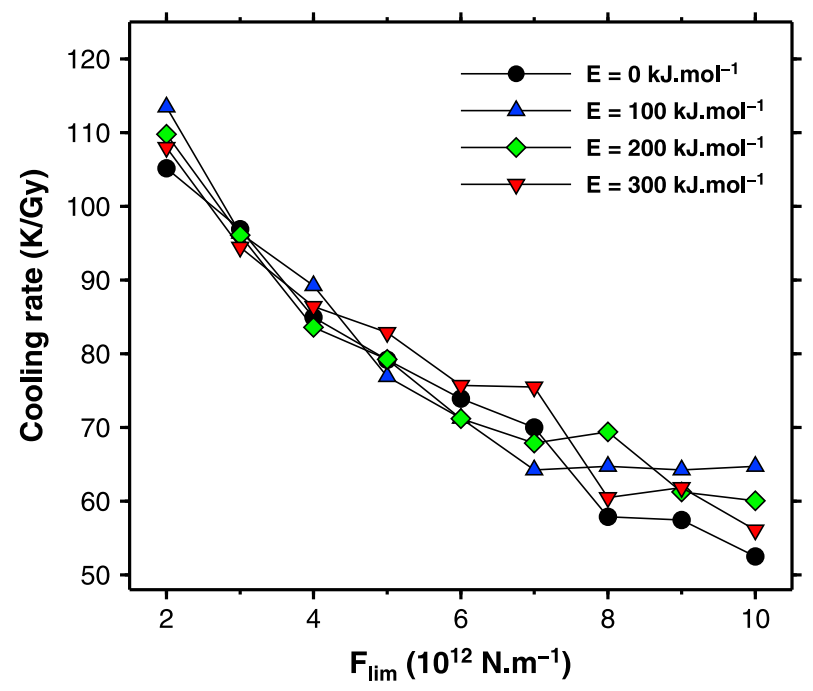

Figure 16. Cooling rate averaged over the last $2.5 \mathrm{Gyr}$, as a function of activation energy $E$ and yield strength $F_{\text {lim. }}$. on the plate length, on whether there is slab pull or not on this plate, and on mantle viscosity. On the long-term and a global scale, taking into account all the plates, Earth's cooling rate depends on seafloor age distribution. The critical parameters controlling this distribution are related to subduction initiation and oceanization by continental breakup, and future studies should focus on these two processes. With our present choice of laws, which yields Earth-like plate velocities and rearrangements, the mantle cooling rate is more dependent on continent dynamics than on mantle rheology. Our model, considering a uniform cooling rate for the core and the mantle, suggests that Earth's cooling mechanisms are controlled by the surface rather than by the mantle, over two different timescales. On the short term, heat flux fluctuations mainly depend on the competition for space among plates. On the long term, secular cooling primarily depends on the ability of the Earth to rejuvenate the oceanic lithosphere by creating new plates.

\section{Acknowledgments}

[59] This work was supported by Brest Métropole Océane and Région Bretagne through the MODENA (M.C. and M.P.) 
and MONDDO (C.G.) projects, by the ANR GiSeLE project (L. H.), by NSF grant EAR-0914712 (C.P.C.) and by INSU-Syster. We thank the Editor J. Tyburczy, as well as three anonymous reviewers, for their constructive comments. We also thank A. Lenardic for his detailed and helpful review and C. Jaupart for supportive and valuable discussions.

\section{References}

Becker, T., C. Conrad, B. Buffett, and R. D. Müller (2009), Past and present seafloor age distributions and the temporal evolution of plate tectonic heat transport, Earth Planet. Sci. Lett., 278, 233-242.

Boruchov, D., S. Gururangan, M. Driscoll, and J. Bussel (2007), Multiagent induction and maintenance therapy for patients with refractory immune thrombocytopenic purpura, Blood, 110(10), 3526-3531.

Buffet, B. (2006), Plate force due to bending at subduction zones, J. Geophys. Res., 111, B09405, doi:10.1029/ 2006JB004295.

Carlson, R. (1981), Boundary forces and plate velocities, Geophys. Res. Lett., 8(9), 958-961.

Carlson, R. (1983), Plate motions, boundary forces, and horizontal temperature gradients: Implications for the driving mechanism, Tectonophysics, 99, 149-164.

Carlson, R., and H. Johnson (1994), On modeling the thermal evolution of the oceanic upper mantle: An assessment of the cooling plate model, J. Geophys. Res., 99(B2), 3201-3214.

Christensen, U. R. (1985), Thermal evolution models for the Earth, J. Geophys. Res., 90, 2995-3007.

Cloetingh, S., R. Wortel, and N. Vlaar (1989), On the initiation of subduction zones, Pure Appl. Geophys., 129, 7-25, doi:10.1007/BF00874622.

Coltice, N., B. Phillips, H. Bertrand, Y. Ricard, and P. Rey (2007), Global warming of the mantle at the origin of flood basalts over supercontinents, Geology, 35, 391-394.

Combes, M., B. Buin, M. Parenthoën, and J. Tisseau (2010), Multiscale multiagent architecture validation by virtual instruments in molecular dynamics experiments, paper presented at International Conference on Computational Science, Simulation of Multiphysics Multiscale Systems Workshop, Univ. of Amsterdam, Amsterdam.

Conrad, C., and B. Hager (1999a), Effects of plate bending and fault strength at subduction zones on plate dynamics, J. Geophys. Res., 104(B8), 17,551-17,571, doi:10.1029/ 1999JB900149.

Conrad, C., and B. Hager (1999b), The thermal evolution of an Earth with strong subduction zones, Geophys. Res. Lett., 26(19), 3041-3044, doi:10.1029/1999GL005397.

Conrad, C., and C. Lithgow-Bertelloni (2002), How mantle slabs drive plate tectonics, Science, 298, 207-209.

Conrad, C., and C. Lithgow-Bertelloni (2004), The temporal evolution of plate driving forces: Importance of "slab suction" versus "slab pull" during the Cenozoic, J. Geophys. Res., 109, B10407, doi:10.1029/2004JB002991.

Corradini, F., and E. Merelli (2005), Hermes: Agent-based middleware for mobile computing, Mobile Comput., 3465, 234-270.

Coulon, A., G. Beslon, and O. Gandrillon (2008), Large multiprotein structures modelling and simulation: The need for mesoscopic models, in Methods in Molecular Biology, vol. 484, Functional Proteomics: Methods and Protocals, Methods Mol. Biol., chap. 4, pp. 537-558, Humana, Totowa, N. J.
Crameri, F., and B. Kaus (2010), Parameters that control lithospheric-scale thermal localization on terrestrial planets, Geophys. Res. Lett., 37, L09308, doi:10.1029/2010GL042921.

Crameri, F., P. J. Tackley, I. Meilick, T. V. Gerya, and B. J. P. Kaus (2012), A free plate surface and weak oceanic crust produce single-sided subduction on Earth, Geophys. Res. Lett., 39, L03306, doi:10.1029/2011GL050046.

Davaille, A., and C. Jaupart (1994), Onset of thermal convection in fluids with temperaturedependent viscosity. application to the oceanic mantle, J. Geophys. Res., 99(B10), 19,853-19,866, doi:10.1029/94JB01405.

Davies, G. (1980), Thermal histories of convective Earth models and constraints on radiogenic heat production in the Earth, J. Geophys. Res., 85, 2517-2530.

DeMets, C., R. Gordon, D. Angus, and S. Stein (1994), Effect of recent revisions to the geomagnetic reversal time scale on estimates of current plate motions, Geophys. Res. Lett., 21(20), 2191-2194.

Desmeulles, G., S. Bonneaud, P. Redou, V. Rodin, and J. Tisseau (2009), In virtuo experiments based on the multiinteraction system framework: The reiscop metamodel, Comput. Model. Eng. Sci., 47(3), 299-330.

Dumoulin, C., M.-P. Doin, D. Arcay, and L. Fleitout (2005), Onset of small-scale instabilities at the base of the lithosphere: Scaling laws and role of preexisting lithospheric structures, Geophys. J. Int., 160, 344-356.

Ferber, J. (1999), Multi Agent Systems: An Introduction to Distributed Artificial Intelligence, Addison Wesley, Harlow, U. K.

Forsyth, D., and S. Uyeda (1975), On the relative importance of the driving forces on plate motion, Geophys. J., 43, 163-200.

Gable, C., R. O'Connell, and B. Travis (1991), Convection in three dimensions with surface plates: Generation of toroidal flow, J. Geophys. Res., 96, 8391-8405.

Gait, A., and J. Lowman (2007), Time-dependence in mantle convection models featuring dynamically evolving plates, Geophys. J. Int., 171, 463-477.

Gait, A., J. Lowman, and C. Gable (2008), Time dependence in 3-D mantle convection models featuring evolving plates: Effect of lower mantle viscosity, J. Geophys. Res., 113, B08409, doi:10.1029/2007JB005538.

Gerya, T., J. Connoly, and D. Yuen (2008), Why is terrestrial subduction one sided?, Geology, 36(1), 43-46.

Goes, S., F. Capitanio, G. Morra, M. Seton, and D. Giardini (2011), Signatures of downgoing plate-buoyancy driven subduction in cenozoic plate motions, Phys. Earth Planet. Inter., 184, 1-13.

Gordon-Spears, D., and W. Spears (2002), Analysis of a phase transition in a physics based multiagent system, in Lecture Notes in Computer Science, vol. 2699, Formal Approaches to Agent Based Systems, pp. 193-207, Springer, Berlin.

Griffiths, R., R. Hackney, and R. van der Hilst (1995), A laboratory investigation of effects of trench migration on the descent of subducted slabs, Earth Planet. Sci. Lett., 133, 1-17.

Grigné, C., and S. Labrosse (2001), Effects of continents on Earth cooling: Thermal blanketing and depletion in radioactive elements, Geophys. Res. Lett., 28, 2707-2710.

Grigné, C., S. Labrosse, and P. Tackley (2005), Convective heat transfer as a function of wavelength: Implications for the cooling of the Earth, J. Geophys. Res., 110, B03409, doi:10.1029/2004JB003376.

Grigné, C., S. Labrosse, and P. Tackley (2007a), Convection under a lid of finite conductivity: Heat flux scaling and 
application to continents, J. Geophys. Res., 112, B08402, doi:10.1029/2005JB004192.

Grigné, C., S. Labrosse, and P. Tackley (2007b), Convection under a lid of finite conductivity in wide aspect ratio models: Effect of continents on the wavelength of mantle flow, J. Geophys. Res., 112, B08403, doi:10.1029/2006JB004297.

Guillou, L., and C. Jaupart (1995), On the effect of continents on mantle convection, J. Geophys. Res., 100, 24,217-24,238.

Guillou-Frottier, L., J. Buttles, and P. Olson (1995), Laboratory experiments on the structure of subducted lithosphere, Earth Planet. Sci. Lett., 133, 19-34.

Gurnis, M. (1988), Large scale mantle convection and the aggregation and dispersal of supercontinents, Nature, 332, 695-699.

Hall, C. E., M. Gurnis, M. Sdrolias, L. L. Lavier, and R. D. Müller (2003), Catastrophic initiation of subduction following forced convergence across fracture zones, Earth Planet. Sci. Lett., 212, 15-30.

Heuret, A., and S. Lallemand (2005), Plate motions, slab dynamics and back-arc deformation, Phys. Earth Planet. Inter., 149, 31-51.

Heuret, A., F. F. Funiciello, C. C. Faccenna, and S. Lallemand (2007), Plate kinematics, slab shape and back-arc stress: A comparison between laboratory models and current subduction zones, Earth Planet. Sci. Lett., 256, 473-483.

Huang, J., S. Zhong, and J. van Hunen (2003), Controls on sublithospheric small-scale convection, J. Geophys. Res., 108(B8), 2405, doi:10.1029/2003JB002456.

Jaupart, C., S. Labrosse, and J. Mareschal (2007), Temperatures, heat and energy in the mantle of the Earth, in Treatise on Geophysics, vol. 7, Mantle Dynamics, edited by D. Bercovici, pp. 253-304, Elsevier, Boston, Mass.

Jochum, K., A. Hoffmann, I. E. H. Seufert, and W. White (1983), K, U and Th in mid-ocean ridge basalt glasses and heat production, $K / U$ and $K / R b$ in the mantle, Nature, 306, 431-436.

Karato, S., and P. Wu (1993), Rheology of the upper mantle: A synthesis, Science, 260, 771-778.

Kerdelo, S., J. Abgrall, M. Parenthoën, and J. Tisseau (2002), In vitro blood coagulation versus in silico blood coagulation an individual-centered approach, in IEEE International Conference on Systems, Man and Cybernetics, pp. 72-76, IEEE Press, Piscataway, N. J.

Kirby, S. H. (1983), Rheology of the lithosphere, Rev. Geophys., 21(6), 1458-1487.

Korenaga, J. (2003), Energetics of mantle convection and the fate of fossil heat, Geophys. Res. Lett., 30(8), 1437, doi:10.1029/2003GL016982.

Labrosse, S., and C. Jaupart (2007), Thermal evolution of the Earth: Secular changes and fluctuations of plate characteristics, Earth Planet. Sci. Lett., 260, 465-481.

Lenardic, A., L. Moresi, A. Jellinek, and M. Manga (2005), Continental insulation, mantle cooling, and the surface area of oceans and continents, Earth Planet. Sci. Lett., 234, 317-333.

Li, Z., et al. (2008), Assembly, configuration, and break-up history of rodinia: A synthesis, Precambrian Res., 160, $179-210$

Lithgow-Bertelloni, C., and M. Richards (1998), The dynamics of Cenozoic and Mesozoic plate motions, Rev. Geophys., 36(1), 27-78, doi:10.1029/97RG02282.

Lowman, J., S. King, and C. Gable (2001), The influence of tectonic plates on mantle convection patterns, temperature and heat flow, Geophys. J. Int., 146, 619-636.

Lowman, J., A. Gait, C. Gable, and H. Kukreja (2008), Plumes anchored by a high viscosity lower mantle in a 3D mantle convection model featuring dynamically evolving plates, Geophys. Res. Lett., 35, L19309, doi:10.1029/2008GL035342.

Loyd, S., T. Becker, C. Conrad, C. Lithgow-Bertelloni, and F. Corsetti (2007), Time variability in cenozoic reconstructions of mantle heat flow: Plate tectonic cycles and implications for Earth thermal evolution, PNAS, 104(36), $14,266-14,271$

Marcenac, P., and S. Giroux (1998), Geamas: A generic architecture for agentoriented simulations of complex processes, Appl. Intell., 8, 247-267.

McKenzie, D. P. (1977), The initiation of trenches: A finite amplitude instability, in Island Arcs, Deep Sea Trenches and Back-Arc Basins, Maurice Ewing Ser., vol. 1, edited by M. Talwani and W. C. Pitman III, pp. 57-61, AGU, Washington, D. C., doi:10.1029/ME001p0057.

McKenzie, D. P., and F. M. Richter (1981), Parameterized thermal convection in a layered region and the thermal history of the Earth, J. Geophys. Res., 86(B12), 11,667-11,680, doi:10.1029/JB086iB12p11667.

Monnereau, M., and S. Quéré (2001), Spherical shell models of mantle convection with tectonic plates, Earth Planet. Sci. Lett., 184, 575-587.

Moresi, L., and V. Solomatov (1998), Mantle convection with a brittle lithosphere: Thoughts on the global tectonic styles of the Earth and Venus, Geophys. J. Int., 133, 669-682.

Mueller, S., and R. Phillips (1991), On the initiation of subduction, J. Geophys. Res., 96(B1), 651-665.

Müller, M., D. Charypar, and M. Gross (2003), Particle-based fluid simulation for interactive applications, paper presented at ACM SIGGRAPH/Eurographics Symposium on Computer Animation, Eurographics Assoc., San Diego, Calif.

Narteau, C. (2007), Formation and evolution of a population of strike slip faults in a multiscale cellular automaton model, Geophys. J. Int., 168, 723-744.

Narteau, C., D. Zhang, O. Rozier, and P. Claudin (2009), Setting the length and time scales of a cellular automaton dune model from the analysis of superimposed bed forms, J. Geophys. Res., 114, F03006, doi:10.1029/2008JF001127.

Nikolaeva, K., T. Gerya, and F. Marques (2011), Numerical analysis of subduction initiation risk along the Atlantic American passive margins, Geology, 39(5), 463-466.

O'Neill, C., A. Lenardic, A. Jellinek, and L. Moresi (2009), Influence of supercontinents on deep mantle flow, Gondwana Res., 15, 276-287, doi:10.1016/j.gr.2008.11.005.

Parenthoën, M., T. Jourdan, and J. Tisseau (2004), Ipas: Interactive phenomenological animation of the sea, paper presented at 14th International Offshore and Polar Engineering Conference, Int. Soc. of Offshore and Polar Eng., Toulon, France.

Parsons, B. (1982), Causes and consequences of the relation between area and age of the ocean floor, J. Geophys. Res., 87, 289-302.

Parsons, B., and F. Richter (1980), A relation between the driving force and geoid anomaly associated with mid-ocean ridges, Earth Planet. Sci. Lett., 51, 445-450.

Pawlowski, M., T. Paterek, D. Kaszlikowski, V. Scarani, A. Winter, and M. Zukowski (2009), Information causality as a physical principle, Nature, 461(7267), 1101-1104.

Phillips, B., and H. Bunge (2005), Heterogeneity and time dependence in 3D spherical mantle convection models with continental drift, Earth Planet. Sci. Lett., 233, 121-135.

Phillips, B., and N. Coltice (2010), Temperature beneath continents as a function of continental cover and convective wavelength, J. Geophys. Res., 115, B04408, doi:10.1029/ 2009JB006600. 
Replumaz, A., H. Karason, R. van der Hilst, J. Besse, and P. Tapponnier (2004), 4-D evolution of SE Asia's mantle from geological reconstructions and seismic tomography, Earth Planet. Sci. Lett., 221, 103-115, doi:10.1016/ s0012-821x(04)00070-6.

Rolf, T. and P. J. Tackley (2011), Focussing of stress by continents in 3D spherical mantle convection with selfconsistent plate tectonics, Geophys. Res. Lett., 38, L18301, doi:10.1029/2011GL048677.

Rowley, D. (2002), Rate of plate creation and destruction: 180 Ma to present, Geol. Soc. Am. Bull., 114(8), 927-933.

Samuel, H., V. Aleksandrov, and B. Deo (2011), The effect of continents on mantle convective stirring, Geophys. Res. Lett., 38, L04307, doi:10.1029/2010GL046056.

Schubert, G., D. Stevenson, and P. Cassen (1980), Whole planet cooling and the radiogenic heat source contents of the Earth and the Moon, J. Geophys. Res., 85, 2531-2538.

Stein, C., and J. Lowman (2010), Response of mantle heat flux to plate evolution, Geophys. Res. Lett., 37, L24201, doi:10.1029/2010GL045283.

Stern, R. (2004), Subduction initiation: spontaneous and induced, Earth Planet. Sci. Lett., 226, 275-292.

Tackley, P. (2000a), Mantle convection and plate tectonics: Toward an integrated physical and chemical theory, Science, 288, 2002-2007.

Tackley, P. (2000b), Self-consistent generation of tectonic plates in time-dependent, three-dimensional mantle convection simulations, Geochem. Geophys. Geosyst., 1(8), 1021, doi:10.1029/2000GC000036.

Toth, J., and M. Gurnis (1998), Dynamics of subduction initiation at preexisting fault zones, J. Geophys. Res., 103(B8), 18,053-18,067, doi:10.1029/98JB01076.
Turcotte, D., and G. Schubert (2002), Geodynamics, Cambridge Univ. Press, Cambridge, U. K.

van der Meer, D., W. Spakman, D. van Hinsbergen, M. Amaru, and T. Torsvik (2010), Towards absolute plate motions constrained by lower-mantle slab remnants, Nat. Geosci., 3, $36-40$.

Vicari, R., C. Flores, A. Silvestre, L. Seixas, M. Ladeira, and H. Coelho (2003), A multiagent intelligent environment for medical knowledge, Artif. Intell. Med., 27(3), 335-366.

Weiss, G. (1999), Multiagent Systems: A Modern Approach to Distributed Artificial Intelligence, MIT Press, Cambridge, Mass.

Wooldridge, M. (2002), An Introduction to Multiagent Systems, John Wiley, New York.

Wu, B., C. Conrad, A. Heuret, C. Lithgow-Bertelloni, and S. Lallemand (2008), Reconciling strong slab pull and weak plate bending: The plate motion constraint on the strength of mantle slabs, Earth Planet. Sci. Lett., 272, 412-421.

Zhang, D., C. Narteau, and O. Rozier (2010), Morphodynamics of barchan and transverse dunes using a cellular automaton model, J. Geophys. Res., 115, F03041, doi:10.1029/ 2009JF001620.

Zhang, N., and S. Zhong (2011), Heat fluxes at the Earth's surface and core-mantle boundary since pangea formation and their implications for the geomagnetic superchrons, Earth Planet. Sci. Lett., 306, 205-216.

Zhong, S., N. Zhang, Z. Li, and J. Roberts (2007), Supercontinent cycles, true polar wander, and very long-wavelength mantle convection, Earth Planet. Sci. Lett., 261, 551-564. 